\title{
Gold Nanorod-Based Nanohybrids for Combinatorial Therapeutics
}

Eva Villar-Alvarez, ${ }^{*}{ }^{\dagger}$ Adriana Cambón, ${ }^{\dagger}$ Alberto Pardo, ${ }^{\dagger}$ Víctor X. Mosquera, ${ }^{\ddagger}$ Alberto Bouzas-Mosquera, ${ }^{\ddagger}$ Antonio Topete, ${ }^{\S \odot}$ Silvia Barbosa, ${ }^{\dagger}$ Pablo Taboada, ${ }^{*}, \dagger$ and Víctor Mosquera

${ }^{\dagger}$ Grupo de Física de Coloides y Polímeros, Departamento de Física de Partículas, Facultad de Física e Instituto de Investigaciones Sanitarias (IDIS), Universidad de Santiago de Compostela, 15782 Santiago de Compostela, Spain

‡Departamento de Cirugía Cardíaca, Complexo Hospitalario Universitario A Coruña, Instituto de Investigación Biomédica de A Coruña (INIBIC), A Coruña, Spain

${ }^{\S}$ Departamento de Fisiología, Centro Universitario de Ciencias de la Salud, Universidad de Guadalajara, Sierra Mojada 950, Guadalajara, Jalisco, Mexico

\section{Supporting Information}

ABSTRACT: In this work, multifunctional nanocarriers consisting of poly(sodium-4-styrenesulfonate) (PSS)/doxorubicin (DOXO)/poly-L-lysine hydrobromide (PLL)/hyaluronic acid (HA)-coated and (PSS/DOXO/ $\mathrm{PLL})_{2}$ /HA-coated gold nanorods were assembled by the layer-by-layer technique with the aims of coupling the plasmonic photothermal properties of the metal nanoparticles for plasmonic hyperthermia and the chemoaction of drug DOXO for potential intended combinatorial cancer therapeutics in the future as well as providing different strategies for the controlled and sustained release of the cargo drug molecules. To do that, DOXO could be successfully loaded onto the hybrid nanoconstructs through electrostatic interactions with high efficiencies of up to ca. $78.3 \pm 6.9 \%$ for the first formed drug layer and $56 \pm 13 \%$ for the second one, with a total efficiency for the whole system $\left[(\mathrm{PSS} / \mathrm{DOXO} / \mathrm{PLL})_{2} / \mathrm{HA}\right.$-coated NRs] of ca. $65.7 \pm$ $1.4 \%$. Nanohybrid internalization was observed to be enhanced by the outer HA layer, which is able to target the CD44 receptors widely overexpressed in some types of cancers as lung, breast, or ovarian ones. Hence, these nanohybrid systems might be versatile nanoplatforms to simultaneously deliver sufficient heat for therapeutic plasmonic hyperthermia and the anticancer drug. Two controlled mechanisms were proposed to modulate the release of the chemodrug, one by means of the enzymatic degradable character of the PLL layer and another by the modulation of the interactions between the polymeric layers through the exploitation of the optical properties of the hybrid particles under near infrared (NIR) laser irradiation. The combination of this bimodal therapeutic approach exerted a synergistic cytotoxic effect on both HeLa and MDA-MB-231 cancer cells in vitro. Cell death mechanisms were also analyzed, elucidating that plasmonic photothermal therapy induces cell necrosis, whereas DOXO activates the cell apoptotic pathway. Therefore, the present NIR laser-induced targeted cancer thermo/chemotherapy represents a novel targeted anticancer strategy with easy control on demand and suitable therapeutic efficacy.

\section{INTRODUCTION}

Cancer is a disease characterized by the uncontrolled growth and spread of abnormal cells originated from inherited DNA damage or induced by environmental factors and is the second cause of death worldwide. For example, 1688780 new cancer cases and 600920 cancer deaths were estimated in 2017 only in USA. ${ }^{1}$ Current cancer treatments include surgery, chemotherapy, and/or radiation. Surgical extirpation is highly effective in primary tumors, but it is limited to surgically recognizable and accessible tumors and thus cancer cells may not be completely removed. Radiation (X-rays, gamma rays, or electrons) is often used to destroy diseased cell and tissues at the molecular level as a complementary approach to eradicate remaining cancer cells after surgery. However, it may cause damages to healthy tissues located close to cancerous cells or within the pathway of the radiation beam. On the other hand, the systematic administration of chemical drugs to kill malignant cells (chemotherapy) is sometimes effective for complete tumor elimination and subsequent patient recovery, but it possesses numerous drawbacks and adverse side effects, for example, (i) side toxicity in healthy tissues as a result of its nonspecificity; (ii) development of drug resistances; (iii) achievement of suboptimal therapeutic concentrations in the diseased cells/tissues as a consequence of poor drug diffusion and accumulation conditioned by tumor structure and vascularization; and so forth. In addition, the impossibility of

Received: July 10, 2018

Accepted: September 20, 2018

Published: October 4, 2018 
an early detection of very small tumors or blood circulating malignant cells also decreases the probability of success of current cancer therapies. Therefore, alternative treatments/ therapies are largely required.

A strategy to overcome the aforementioned drawbacks can be the combination of antitumor drugs with colloidal nanoparticles (NPs) used as nanocarriers or nanoreservoirs, which emerges as an interesting area of research to overcome the limitations, for example, of current chemotherapies. ${ }^{2}$ Drug nanocarriers possess several advantages over free drugs, including (i) their nanometer size, which can exploit the physiological abnormalities of tumoral cells/tissues to favor their selective accumulation in the diseased areas through the enhanced permeation and retention effect; ${ }^{3}$ (ii) their capability to transport high drug payloads with prolonged half-life and reduced toxicity, thus significantly lowering the therapeutic dose required for effective treatment $\left(\mathrm{IC}_{50}\right) ;$ (iii) their ability to evade the immune system; ${ }^{4,5}$ and (iv) their potential for selective targeting cancer cells and tissues thanks to their potential high surface density to attach specific ligands which can bind to overexpressed receptors in cancerous cells (the socalled active targeting). ${ }^{5}$

Several types of NPs have been already proved for effective anticancer therapies including micelles; ${ }^{6}$ liposomes; ${ }^{7}$ polymeric $\mathrm{NPs}^{8}{ }^{8}$ dendrimers; ${ }^{9}$ carbon-based nanostructures as carbon nanotubes; ${ }^{10}$ gold, ${ }^{11}$ silver, ${ }^{12}$ and iron oxide NPs; ${ }^{13}$ semiconductor quantum dots; ${ }^{14}$ and viral capsids. ${ }^{15}$ Among all these types of particles, gold (Au) NPs (nanospheres, nanorods, nanoshells, nanocages, and nanostars) are gaining great importance for several reasons as follows: (i) Au NPs are considered to be relatively nontoxic and nonreactive and are therefore suitable for in vivo applications; ${ }^{16}$ (ii) they exhibit outstanding optical properties, for example, the generation of localized surface plasmons; ${ }^{17}$ (iii) their nature allows the facile addition of new surface functionalities; ${ }^{18}$ and (iv) their size, morphology, and monodispersity can be easily controlled during the synthesis process, allowing the fine-tuning of their optical properties from the visible to the near-infrared region (NIR) region of the electromagnetic spectrum. ${ }^{19}$

Compared with other available Au NPs, Au nanorods (GNRs) are especially attractive as a consequence of their anisotropic structure. This morphology allows the collective coherent oscillation of conduction electrons on the particle surface upon interaction with light of suitable wavelength to occur mainly in two directions, that is, along the short and long axes of the NP, resulting in the generation of the so-called transverse and longitudinal localized surface plasmon bands (LPSRs). ${ }^{20}$ The subsequent main relaxation process usually involves a high conversion of light into heat, which is released to the medium. The GNR transverse LPSR band usually appears in the visible region of the electromagnetic spectrum, whereas the longitudinal one usually appears in the NIR, that is, within the so-called first biological window, which makes this type of particles really interesting for biological applications. $^{21}$ GNRs also exhibit the most suitable NIR absorption cross sections if compared with other $\mathrm{Au} \mathrm{NPs,}{ }^{22}$ demonstrating extremely efficient NIR photothermal heat conversion while reducing both the energy required for phototreatment ( thus minimizing the affectation of surrounding healthy tissues) and photobleaching. ${ }^{23}$ The generated thermal energy can induce temperature increases of more than $20{ }^{\circ} \mathrm{C}$ (i.e., hyperthermia), which can thereby induce therapeutic tumor/cell tissue ablation (above $43-45{ }^{\circ} \mathrm{C}$ ) or thermal tissue sensitization (below $43{ }^{\circ} \mathrm{C}$ ) to optimize the efficacy of complementary therapies such as chemo- or radiotherapies. $^{24,25}$ In this regard, NIR plasmonic photothermal therapy (PPTT) using GNRs was first demonstrated by El-Sayed's group, who showed the destruction of cancer cells after exposure to a focused NIR light beam without affectation of healthy ones. ${ }^{26}$ Other researchers also demonstrated the same great feasibility of tumor photothermal ablation using different types of gold, other metal, and organic NPs. ${ }^{25,27-29}$ Moreover, it is worth noting that GNRs possess much larger surface areas per volume than that of, for example, spherical Au NPs, which make them an attractive nanocarrier with large payload capability for codelivering several types of therapeutical agents as antibodies, ${ }^{30}$ chemotherapeutic drugs, ${ }^{31}$ or nucleic acids. ${ }^{32}$ To do this, suitable modification of the particle surfaces by different strategies such as ligand exchange, ${ }^{33}$ hydrophobic/electrostatic adsorption, ${ }^{34}$ layer-bylayer (LbL) assembly, ${ }^{35}$ or silica coating ${ }^{36}$ is required, which also enables the controlled release of the payloads either by internal $(\mathrm{pH}$, enzymes, temperature, etc) or external (light, ultrasounds, electric and magnetic fields, etc.) stimuli without compromising the particle stability in biological fluids. Then, it is expected that the combination of PPTT provided by the plasmonic properties of GNRs and chemotherapy would be able to provide synergistic therapeutic benefits in the treatment of tumoral cells and a way to overcome multidrug resistances. ${ }^{37}$

For these reasons, in this work, we developed a therapeutical nanocarrier based on the exploitation of the plasmonic properties of GNRs and their easy surface modification by the $\mathrm{LbL}$ assembly technique to allow the loading of large amounts of the chemodrug doxorubicin (DOXO), while ensuring a high colloidal stability in biological fluids, a controlled and sustained release of the cargo, and high cell uptake and internalization levels. DOXO is an anthracycline antibiotic widely used to treat a wide range of cancers by intercalating DNA and inhibiting macromolecular biosynthesis. Like other anticancer drugs, several drawbacks are associated to its periodical administration such as poor selectivity, ${ }^{38}$ dosedependent cardiotoxicity, ${ }^{39}$ and/or the induction of multidrug resistances in cancer cells ${ }^{40}$ so that new forms of administration are largely required.

Here, GNRs were obtained by a wet seed-mediated chemical reduction method. ${ }^{26}$ The resulting particles were coated with alternating layers of the anionically charged poly(styrene sulfonate) (PSS) and the cationically charged poly(lysine) (PLL) polymers to mask the toxic hexadecyltrimethyl ammonium bromide (CTAB) layer resulting from the synthesis process after a preliminary washing step. ${ }^{34,35}$ DOXO was introduced in the assembled surface coating in the form of one or two layers by exploiting the electrostatic interactions with the underlying PSS layer. Finally, hyaluronic acid (HA) was used as the outer external polymeric layer thanks to their ability to avoid nonspecific interactions with serum components ${ }^{41}$ as well as to target and bind overexpressed CD44 receptors in some types of cancerous cells, such as cervical HeLa and breast MDA-MB-231, allowing an active targeting strategy to localize the hybrid particles within the diseased cells/tissues. ${ }^{42}$ Thanks to the clever choice of the coating polymers, drug release could be triggered either by means of the enzymatically biodegradable character of the PLL polymer and/or by exploitation of the NIR optical properties of GNRs, which enable the modulation of the attraction between the polymeric layers at the surface particle coating 
under NIR light irradiation by controlling the size of the illuminated area, exposure time, and light fluency. Additionally, the combination of the generated NIR-induced hyperthermia and the controlled and sustained release of the chemodrug might allow the obtention of combinatorial synergistic therapeutical effects provided by the cell-internalized hybrid nanoplatforms as elucidated from transmission electron microscopy (TEM), flow cytometry, and fluorescence microscopy in vitro experiments.

\section{RESULTS AND DISCUSSION}

2.1. DOXO Entrapment. GNRs were prepared through the well-established two-step seed-mediated growth method with slight modifications (see Experimental Section). ${ }^{26}$ The resulting GNRs exhibit a size of $33 \mathrm{~nm} \times 9 \mathrm{~nm}$. To mask the $\mathrm{CTAB}$ layer and avoid their associated toxicity as well as the provide the obtained metallic NPs with sufficient colloidal stability, triggered controlled cargo release, and active targeting abilities, NP surfaces were modified by means of the LbL assembly technique. In this manner, using the LbL method, multilayers of the polyelectrolyte (PE) anionic PSS, cationic PLL, and anionic HA as well as the chemodrug DOXO were successfully deposited onto the GNR surfaces.

Herein, CTAB facilitated the electrostatic adsorption of the anionic PSS PE. The same interactions were further used for the subsequent adsorption of the positively charged DOXO by exploiting the protonation of the amino group in the sugar base moiety of its molecular structure. ${ }^{43}$ To achieve complete charge reversal, an additional cationic PLL layer was deposited. Finally, a last layer of HA was associated to decrease the net positive electrical charge of the hybrid nanoconstruct to avoid potential toxic effects and to provide specific targeting to CD44 receptors commonly overexpressed in the membrane surfaces of several types of malignant stem and cancerous cells. $^{42}$

Next, we evaluated the maximum amount of antineoplasic able to be adsorbed within the particle coating in the form of a single drug layer. To do that, different amounts of DOXO were assembled via LbL to PSS-coated GNRs previously prepared. The successful loading of the cargo onto the metallic NPs was confirmed by UV-vis spectrophotometry. Figure S1 confirms the presence of the characteristic absorption peak of DOXO at ca. $490 \mathrm{~nm}$, which becomes more intense as more DOXO is adsorbed onto the metallic NPs. Moreover, a progressive red shift of the longitudinal LPSR band of GNRs is also observed as a consequence of changes in the local dielectric environment of the NPs as more drug is located near the metal surface.

The loading capacities (LCs) and entrapment efficiencies (EEs) of DOXO on PSS-coated GNRs at different initial fed DOXO (IFD) concentrations are displayed in Table 1. From $150 \mu \mathrm{g}$ of initial fed drug, the loaded DOXO amount is almost

Table 1. DOXO EE and LC on PSS-Coated GNRs $(\sim 1 \times$ $10^{11} \mathrm{NP} / \mathrm{mL}$ ) through the LbL Assembly Technique as a Function of the IFD Mass

$\begin{array}{cccc}\text { IFD }(\mu \mathrm{g}) & \text { loaded drug }(\mu \mathrm{g}) & \text { EE }(\%) & \text { LC }(\%) \\ 50 & 2.70 \pm 0.81 & 5.4 & 5.9 \\ 100 & 33.5 \pm 4.6 & 16.8 & 43.8 \\ 150 & 76.3 \pm 1.0 & 76.3 & 64.0 \\ 200 & 86.6 \pm 1.2 & 57.7 & 66.9 \\ 300 & 78.6 \pm 3.6 & 26.2 & 64.7\end{array}$

constant, suggesting that the saturation of the particle surface was achieved, with averaged LCs of ca. $65 \%(\sim 80 \mu \mathrm{g}$ DOXO in $1 \mathrm{~mL}$ GNRs at $1 \times 10^{11} \mathrm{NP} / \mathrm{mL}$ ) and EEs of ca. $80 \%$. This is in agreement with the progressive increase in the observed negative particle $\zeta$-potential values up to ca. $150 \mu \mathrm{m}$ fed drug and their subsequent leveling off at larger DOXO concentrations (Figure S1b). Thus, for further experiments, we decided to use $150 \mu \mathrm{g}$ as the IFD.

2.2. Characterization of DOXO-Loaded GNRs. Once the ability of DOXO to self-assemble on the GNR surfaces by the LbL technique was confirmed, then, the construction of DOXO-loaded GNRs bearing one (denoted as PSS/DOXOPLL/HA-coated GNRs) or two DOXO [denoted as (PSS/ DOXO-PLL) $)_{2}$ /HA-coated GNRs] coating layers was afforded (see Scheme 1). The latter nanoconstruct was designed to

Scheme 1. Schematic Representation of PSS/DOXO/PLL/ HA-Coated (Left) and (PSS/DOXO/PLL) 2 /HA-Coated GNRs (Right)

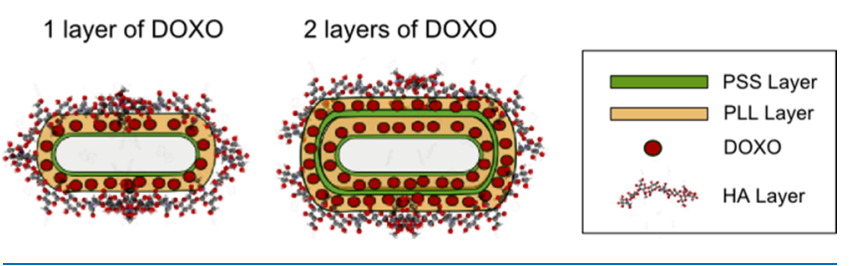

additionally enhance the loaded DOXO concentration in the nanoplatform. These coated GNRs were characterized by UVvis spectroscopy, $\zeta$-potential measurements, dynamic light scattering (DLS), and TEM.

Figure 1a,b shows the UV-vis spectra after each deposition step for (PSS/DOXO/PLL) $2 /$ HA-coated GNRs. It was observed that the longitudinal plasmon absorption peak of GNRs shifts after PE adsorption as a consequence of the extreme sensitivity of the particles to the dielectric properties of the surrounding environment, ${ }^{43}$ thus confirming the successful layer adsorption. Any coating onto the NP surfaces involves a change in the dielectric properties of the particle surroundings, giving rise to a similar effect as immersing the particles in a continuous medium of different refractive indexes (RIs) and hence shifting the position of the longitudinal LSPR maximum (see below). DOXO absorption was confirmed by the enhancement of the band located at $490 \mathrm{~nm}$, which increases with the number of DOXO layers (Figure 1b). Moreover, a relative small broadening of the absorption bands after layer depositions was noted, particularly after the first lysine deposited layer, which suggests the presence of some minimal particle aggregation after the successive coating steps.

For DOXO, PLL, and HA coating layers, a red shift in the longitudinal LSPR band is observed; particularly, for PLL, this red shift might be also influence by some interparticle coupling resulting from the slight observed particle aggregation. In contrast, a blue shift is observed for the PSS coating (see Figure $1 \mathrm{~b}$ ). Blue shifts of the plasmon bands after polymer deposition have been related to polymer unwrapping, ${ }^{44}$ but this is not the case as observed from the change from positive to negative of $\zeta$-potential values (Figure 1c). Hence, the observed variations can be ascribed to the different RIs of the PEs compared to that of the CTAB surfactant. ${ }^{45}$ On the other hand, a certain damping of the longitudinal LPSR peak progressively took place as more polymeric layers are added on the GNR surfaces (see Figure 1a,b). This effect can be the 

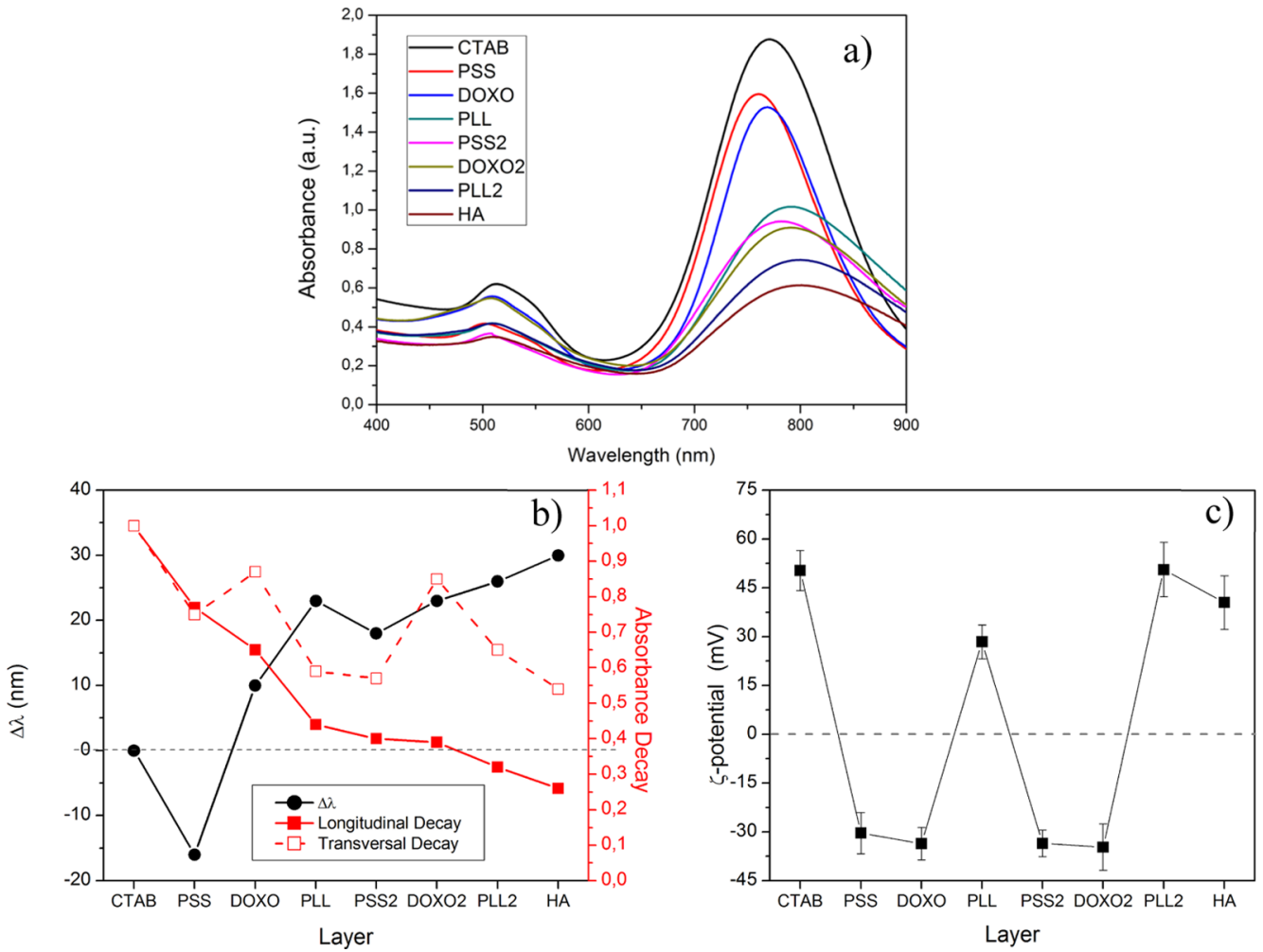

Figure 1. (a) UV-vis absorbance spectra for each PE layer deposited onto GNRs for (a) (PSS/DOXO/PLL) 2 /HA-coated GNRs. (b) Longitudinal LSPR shifts (black $\mathbf{O}$ ), longitudinal (red $\boldsymbol{\square}$ ) and transversal (red $\square$ ) absorbance decays, and (c) $\zeta$-potentials (black $\boldsymbol{\square}$ ) after each coating step for (PSS/DOXO/PLL) 2 /HA-coated GNRs. The LSPR shift of coated GNRs with layer $i$ is defined as $\Delta \lambda=\lambda(i)-\lambda(\mathrm{CTAB})$. Longitudinal and transversal decays are constructed as the ratio between the optical absorbance in layer $i$ regarding that of the $\mathrm{CTAB}$ layer: $\operatorname{decay}(\mathrm{SPR})=\mathrm{abs}(i) /$ abs(CTAB). The lines are only to guide the eye.

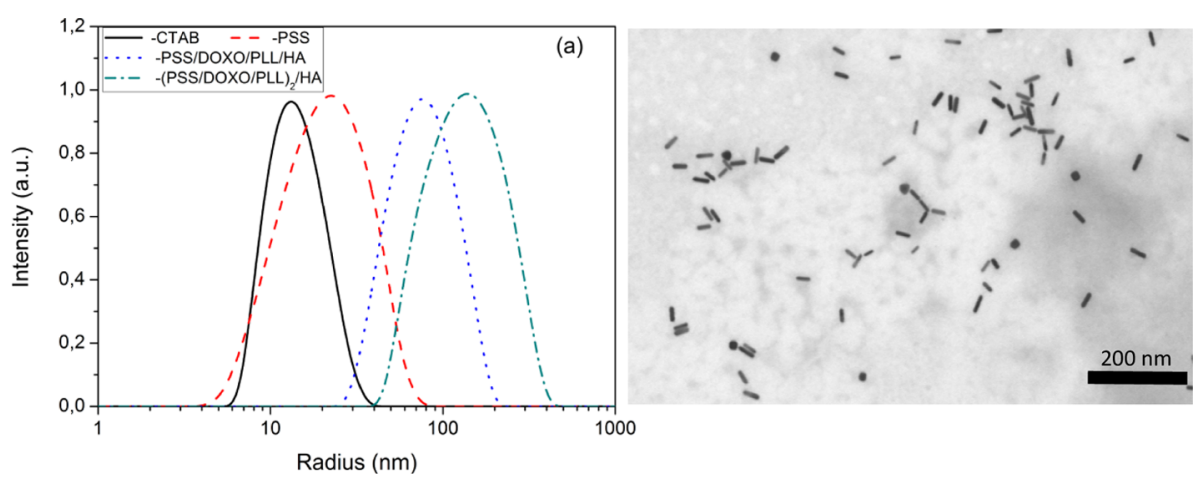

Figure 2. Hydrodynamic radii for (a) CTAB-coated (black), PSS-coated (red), PSS/DOXO/PLL-HA-coated (blue), and (PSS/DOXO/PLL) $2^{-}$ HA-coated (green) GNRs. (b) Scanning TEM image of (PSS/DOXO/PLL) $2 /$ HA-coated GNRs.

result of a reduction of (i) the adsorption of part of the incoming light and/or (ii) the electronic oscillations on the metallic surface. ${ }^{46}$ Conversely, the absorbance corresponding to the transversal plasmon band is barely constant except when DOXO is adsorbed, where a certain increment is noted (Figure 1b) as a consequence of the contribution of the drug absorption peak at ca. 490-495 $\mathrm{nm}$.

$\zeta$-Potential data (Figure 1c) revealed a reversal in the electrical surface charge of GNRs after the deposition of each adsorbed layer except for DOXO one, as mentioned above. The characteristic zig-zag profile corroborates the layering of alternatively charged PEs with two intermediate drug layers. The assembly of the last HA layer was designed taking into consideration that slightly positively charged NPs should be more effective in interacting with the negatively charged cell membranes, as mentioned in previous chapters. ${ }^{35,47}$ Therefore, the amount of HA incorporated was such to decrease the net positive surface charge of the NPs while avoiding complete charge reversal.

Figure 2 shows the population hydrodynamic size distributions measured by DLS for PSS/DOXO/PLL/HAcoated and (PSS/DOXO/PLL) $2 / \mathrm{HA}$-coated GNRs. Here, it is necessary to bear in mind that DLS data are calculated on the assumption of spherical geometries so the obtained hydrodynamic radii should be taken as a bare approximation. The hydrodynamic dimensions of the hybrid nanoplatforms increased as the number of wrapped layers did (e.g., a single PSS layer led to a size increase of ca. $5 \mathrm{~nm}$ ), and particle sizes increased up to ca. $77.0 \pm 4.5$ and $151.3 \pm 7.1 \mathrm{~nm}$ for PSS/ $\mathrm{DOXO} / \mathrm{PLL} / \mathrm{HA}$-coated GNRs and (PSS/DOXO/PLL) $2 /$ 

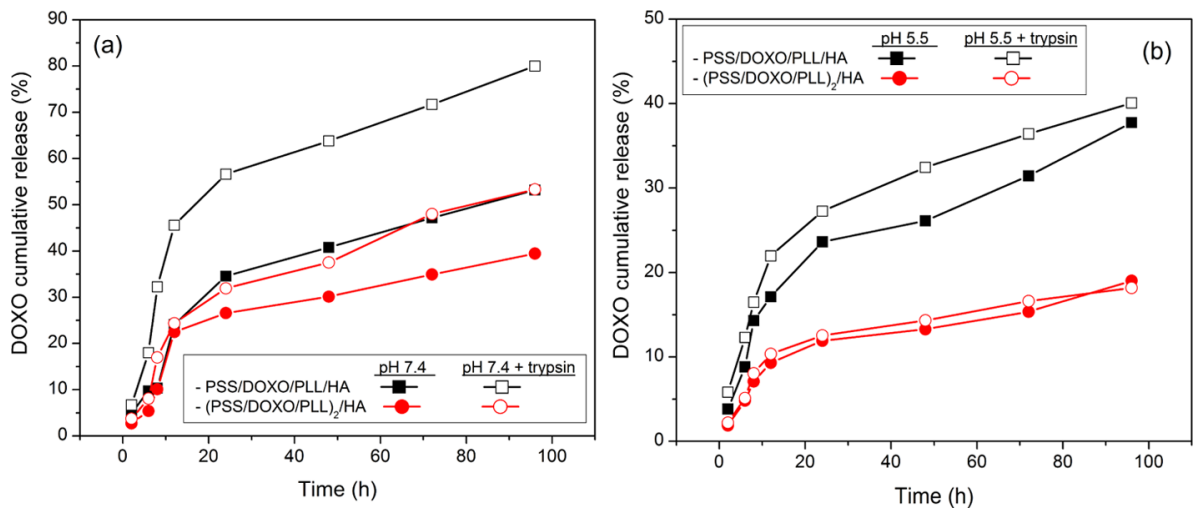

Figure 3. DOXO cumulative release profiles at (a) $\mathrm{pH} 7.4$ and (b) $\mathrm{pH} 5.5$ for PSS/DOXO/PLL/HA-coated (squares) and (PSS/DOXO/PLL) 2 / HA-coated GNRs (circles) in the absence (black $\mathbf{\square}$, red $\bullet$ ) and presence (black $\square$, red $\bigcirc$ ) of trypsin. The lines are only to guide the eye. The relative standard deviation (SD) was found less than $10.0 \%$. Error bars were not included for clarity.

HA-coated ones, respectively. These size increments might be especially related to the swelling of the outer HA layer in aqueous environments, ${ }^{48}$ but some little clusterization of the nanoplatforms cannot be completely disregarded. To note some potential contribution from particle aggregation or bridging between GNRs, TEM images were also acquired. Almost negligible signs of aggregation and/or bridging were noted. The coating layers were hardly observed, provided that they did not offer enough contrast.

Next, the EE for a chosen initial feed of $150 \mu \mathrm{g}$ of DOXO in $1 \mathrm{~mL}$ of PSS-coated GNRs at OD $\approx 1\left(\mathrm{ca} .5 \times 10^{14} \mathrm{NP} / \mathrm{mL}\right)$ was estimated to be ca. $78.3 \pm 6.9 \%$ for the first layer of the adsorbed drug and $56 \pm 13 \%$ for the second one, with a total $\mathrm{EE}$ of ca. $65.7 \pm 1.4 \%$ for $(\mathrm{PSS} / \mathrm{DOXO} / \mathrm{PLL})_{2} / \mathrm{HA}$-coated GNRs. Similar decreases in EE upon sequential entrapment of drugs in several layers have been also reported elsewhere. ${ }^{49}$ The LCs were $41.5 \pm 7.9$ and $39.4 \pm 5.4 \%$ for the first and second drug layers, respectively, with a whole LC of $51 \pm 13 \%$, which highlights the outstanding capacity of these hybrid nanoplatforms to entrap DOXO in the polymeric surface layers.

2.3. DOXO Release from Hybrid GNRs. We next determined the in vitro cumulative DOXO release profiles from PSS/DOXO/PLL/HA-coated and (PSS/DOXO/PLL) 2 / HA-coated GNRs at different conditions, in particular, at physiological $\mathrm{pH} 7.4$ and $\mathrm{pH} 5.5$, which correspond to the acidic microenvironment of the cell cytoplasm, in the presence of $10 \%(\mathrm{v} / \mathrm{v})$ fetal bovine serum (FBS). Moreover, the influence of both endogenous and exogenous triggers as enzymes (proteases) and NIR light in the drug release profiles and rates was also analyzed.

2.3.1. Enzymatic-Assisted Drug Release. The biodegradability of the PLL polymer by endogenous proteases such as lysosomal cathepsin B, often upregulated in cancerous and inflamed cells, and trypsin may confer a slow degradation of the polymeric layer inside the cells and enable a gradual triggered DOXO release from the particles, which might result in a sustained therapeutic effect at much lower doses than that of the administered free drug.

To study DOXO release from both PSS/DOXO/PLL/HAcoated and (PSS/DOXO/PLL) 2 /HA-coated GNRs, the hybrid particles were incubated at $37^{\circ} \mathrm{C}$ in the presence and absence of trypsin at both pHs 7.4 and 5.5 supplemented with $10 \%$ (v/ v) FBS for 4 days (Figure 3). The release profiles initially displayed a burst phase followed by a much slower release pattern for both types of drug-loaded particles at both solution conditions. At $\mathrm{pH} 7.4$ in the absence of the enzyme, PSS/ DOXO/PLL/HA-coated GNRs released ca. $50 \%$ of the loaded cargo in $96 \mathrm{~h}$, whereas (PSS/DOXO/PLL) $2 / \mathrm{HA}$-coated ones only released ca. $35 \%$ (Figure $3 \mathrm{a}$ ), in agreement with the much slower drug diffusion from the inner coating layer. In the presence of trypsin, PSS/DOXO/PLL/HA-coated GNRs released ca. $85 \%$ of the cargo, whereas (PSS/DOXO/PLL) $2 /$ HA-coated ones released ca. $50 \%$, which agrees with (i) the degradation of PLL when the protease is present, thus facilitating drug diffusion out of the particles and (ii) the larger resistance of the (PSS/DOXO/PLL) $2 / \mathrm{HA}$ coating layer to enzymatic degradation, offering an enhanced cargo protection and lowering the release rate. ${ }^{50,51}$ An additional contribution to drug diffusion at physiological $\mathrm{pH}$ might also stem from the reduced ionization state of the drug $\left(\mathrm{p} K_{\mathrm{a}}\right.$ of DOXO ca. 8.2), which results in a weakening of electrostatic interactions with the underlying anionic PSS polymeric layer. ${ }^{51}$

Under acidic conditions (see Figure 3b), DOXO cumulative releases from the hybrid particles were much slower. For example, in the presence of trypsin, DOXO released after $96 \mathrm{~h}$ reached ca. 40 and 20\% for PSS/DOXO/PLL/HA-coated and (PSS/DOXO/PLL) $2 / \mathrm{HA}$-coated GNRs, respectively, in contrast to 85 and $50 \%$ at physiological $\mathrm{pH}$. In addition, differences in DOXO release rates and extents from PSS/ $\mathrm{DOXO} / \mathrm{PLL} / \mathrm{HA}$-coated and (PSS/DOXO/PLL) $2 / \mathrm{HA}$ coated GNRs in the presence and absence of the enzyme were much smaller. Several factors may contribute to the observed behavior. At $\mathrm{pH}$ 5.5, PLL is more densely charged and adopts a random coil conformation, ${ }^{52}$ which should facilitate the establishment of electrostatic interactions and entanglements with the underlying PSS layer, compacting the $\mathrm{PE}$ coating and thus reducing drug diffusion. Moreover, DOXO molecules are positively charged at acidic $\mathrm{pH}$, favoring the attraction with the PSS layer/s. This effect is specially noted for (PSS/DOXO/PLL) $2 / \mathrm{HA}$-coated GNRs, in which the accessibility of the enzyme to the PE coating within the time range analyzed seemed to be largely precluded. In summary, the release rates were generally faster in the presence of the degrading enzyme as a consequence of PLL degradation, and the amount of released drug depended on the number of layers covering the particles and the solution conditions. ${ }^{53}$

2.3.2. NIR Light-Induced Release. The possibility of triggering DOXO release from the hybrid NPs by using NIR light irradiation matching the longitudinal LPSR peak of GNRs 

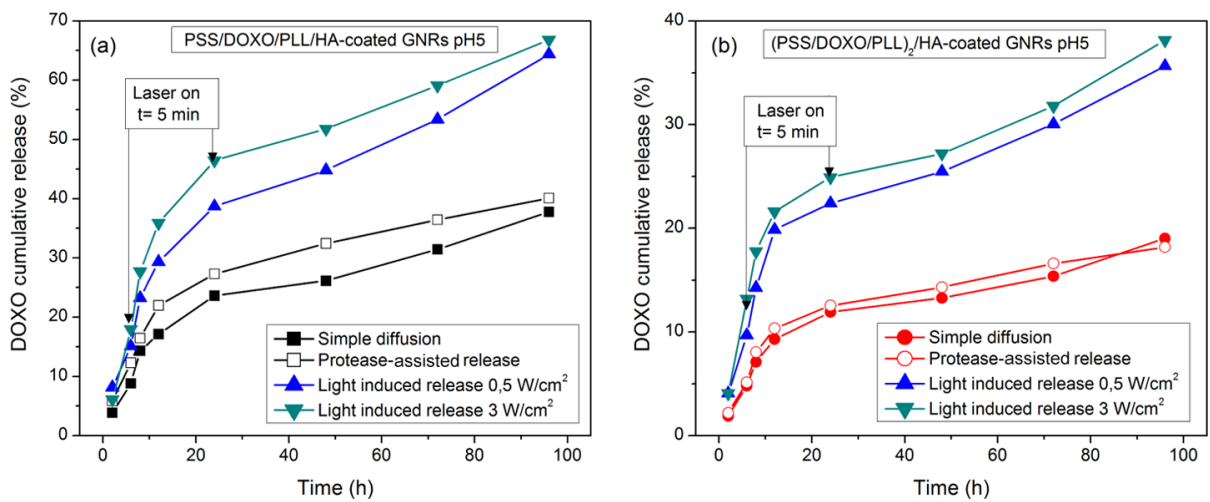

Figure 4. NIR-induced DOXO release from (a) PSS/DOXO/PLL/HA-coated and (b) (PSS/DOXO/PLL) 2 /HA-coated GNRs. The laser powers were 3.0 (green $\boldsymbol{\nabla}$ ) and 0.5 (blue $\boldsymbol{\Lambda}$ ) W/ $\mathrm{cm}^{2}$. Simple drug diffusion (black $\mathbf{\square}$, red $\boldsymbol{\bullet}$ ) and enzymatic-assisted release (black $\square$, red $\bigcirc$ ) are also shown for comparison. The relative SD was found to be less than $10.0 \%$. Error bars were not included for clarity. The lines are only to guide the eye.

was also explored. Hence, in vitro cumulative DOXO release profiles at acidic conditions ( $\mathrm{pH} 5.5$ ) in the presence of $10 \%$ $(\mathrm{v} / \mathrm{v})$ FBS under NIR laser irradiation of $808 \mathrm{~nm}$ and fluencies of 0.5 and $3.0 \mathrm{~W} / \mathrm{cm}^{2}$ applied for $5 \mathrm{~min}$ at 6 and $24 \mathrm{~h}$ of incubation were obtained (Figure 4).

Similar to enzymatic-assisted release, NIR-induced DOXO release profiles displayed a burst phase at short incubation times (within ca. 12-20 h of incubation) followed by a more sustained release phase. The release extent was observed to be greatly enhanced in the presence of NIR light irradiation compared to protease-assisted and diffusion-only cumulative releases for both types of hybrid particles (Figure 4). For example, meanwhile the PLL coating was hardly degraded by trypsin at short incubation times $(<24 \mathrm{~h})$, laser irradiation achieved a much faster destabilization of the PE layers through localized heating around each NP and the potential generation of hot electrons, which modifies PE-drug interactions and allows DOXO release. ${ }^{54}$ For PSS/DOXO/PLL/HA-coated GNRs (Figure 4a), the release extent and rate were slightly larger under NIR illumination of $3 \mathrm{~W} / \mathrm{cm}^{2}$ than those at 0.5 $\mathrm{W} / \mathrm{cm}^{2}$, with ca. 65 and $60 \%$ of drug release after $96 \mathrm{~h}$ of incubation, respectively. Light-induced DOXO release from (PSS/DOXO/PLL) 2 /HA-coated GNRs was ca. $37 \%$ with no influence of the applied light intensity and lower than those obtained for the former types of particles (Figure $6 \mathrm{~b}$ ). We hypothesized that light absorption by the multilayered structure (see above) might involve the used fluencies to be insufficient to correctly modulate the PE interactions (Figure $6 b)$.

2.4. Particle Uptake and DOXO Release in Vitro. The uptake and cellular distribution of PSS/DOXO/PLL/HAcoated and (PSS/DOXO/PLL) $2 / \mathrm{HA}$-coated GNRs were analyzed by fluorescence microscopy in the absence and presence of NIR light irradiation $\left(0.5 \mathrm{~W} / \mathrm{cm}^{2}, 5 \mathrm{~min}\right)$ for $24 \mathrm{~h}$ by taking advantage of the intrinsic fluorescent properties of DOXO. As an additional control, PSS/PLL/HA-coated GNRs were used to disregard any potential interference from light reflection originated by the hybrid particles. In this manner, the red fluorescence could be solely assigned to the presence of the drug.

Figure 5 shows that both PSS/DOXO/PLL/HA-coated and (PSS/DOXO/PLL) 2 /HA-coated GNRs were internalized by $\mathrm{HeLa}$ cells, as observed for the red fluorescence corresponding to DOXO released inside the cells, similar as that observed for the administered free drug used as the reference. In the

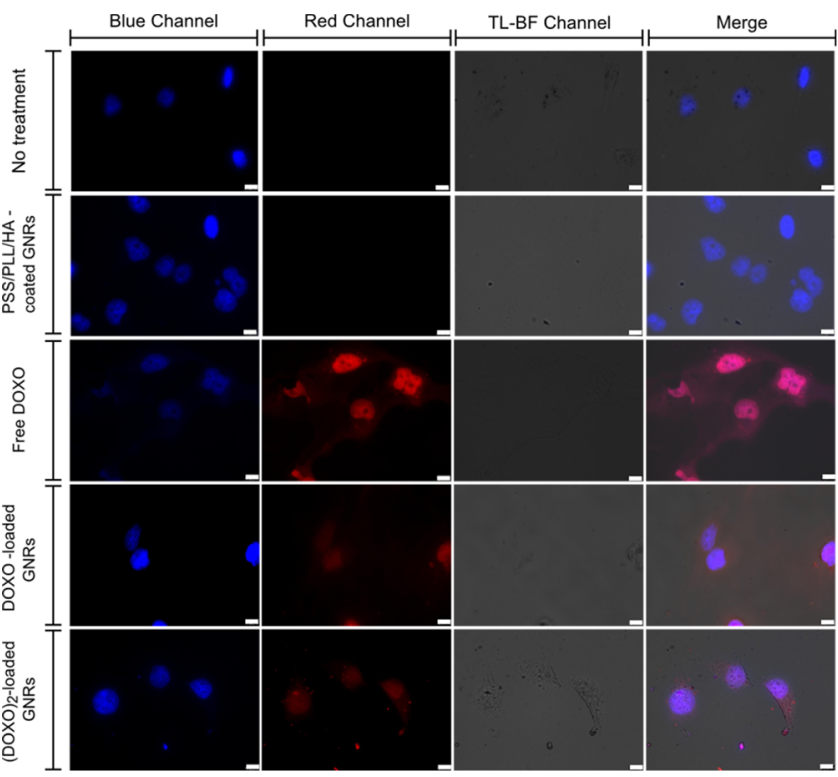

Figure 5. Fluorescence microscopy images of (from top to bottom): bare HeLa cells, bare PSS/PLL/HA-coated GNRs, free DOXO, PSS/ DOXO/PLL/HA-coated GNRs, and (PSS/DOXO/PLL) 2 /HAcoated GNRs after $4 \mathrm{~h}$ of internalization. The blue channel shows the fluorescence from cell nuclei stained with 4',6-diamidino-2phenylindole (DAPI; $\lambda_{\mathrm{ex}}=355 \mathrm{~nm}$ ); the red channel shows the DOXO fluorescence signal; the TL-BF channel displays the optical direct bright field images; and the merged images show the combination of the three previous channels. Scale bars are $10 \mu \mathrm{m}$.

absence of NIR light irradiation, free DOXO is able to penetrate the cell nuclei within $4 \mathrm{~h}$ of incubation. Fluorescent signals of DOXO released from PSS/DOXO/PLL/HA-coated and $(\mathrm{PSS} / \mathrm{DOXO} / \mathrm{PLL})_{2} / \mathrm{HA}$-coated GNRs were less intense at this time point and mainly located in the cell cytoplasm, which agrees with the slower and sustained release of the drug from the NPs (see Figure 3). It is known that DOXO can be quickly transported into cells, entering the active site (nuclei) by passive diffusion. In contrast, DOXO-loaded GNRs are internalized in cells by an endocytosis-related mechanism and are too large to cross the membrane of cell nuclei so only released DOXO from particles can diffuse into. ${ }^{55}$ This fact was corroborated through three-dimensional (3D) image reconstruction of cells upon incubation with (PSS/DOXO/PLL) $2 /$ 

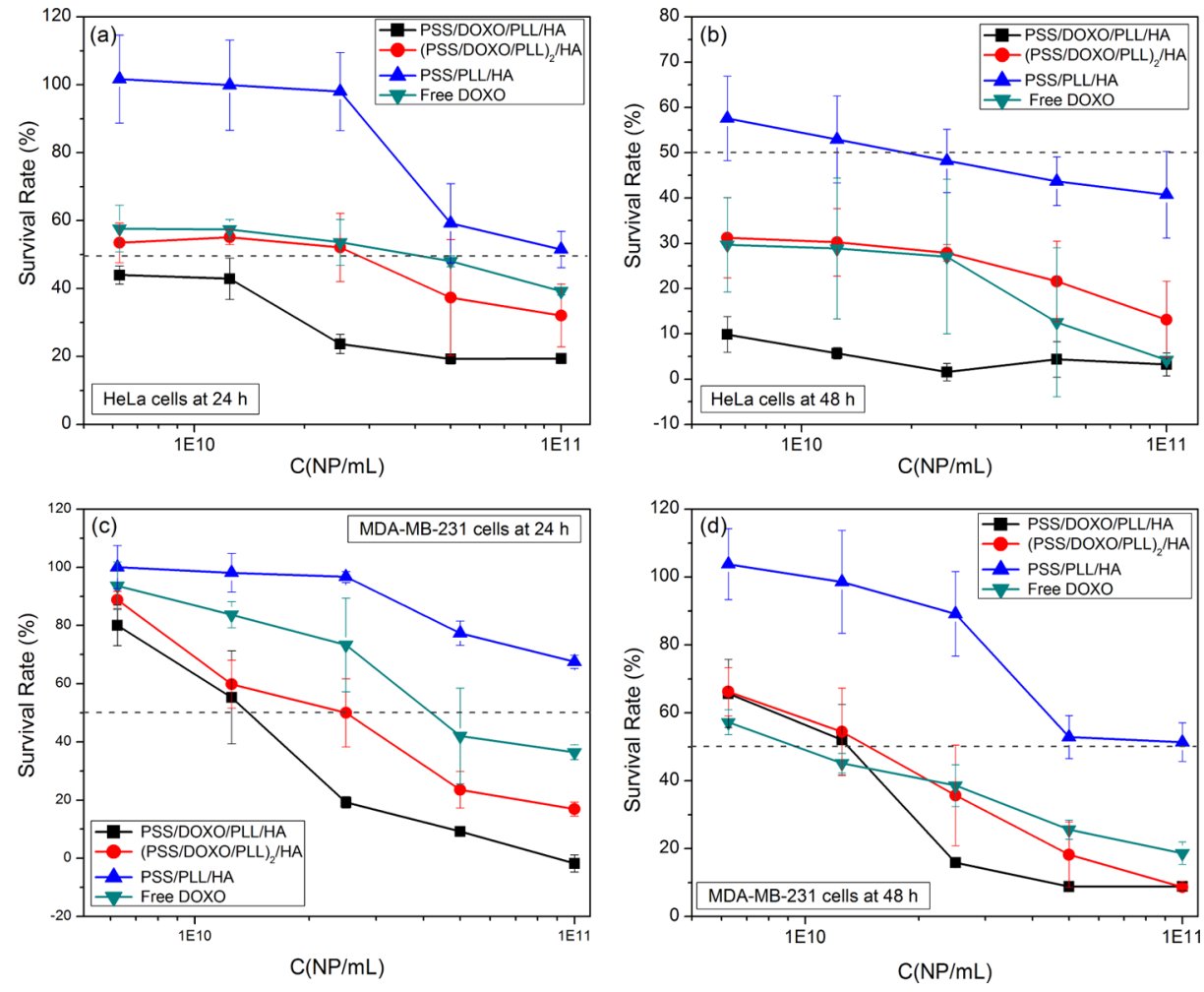

Figure 6. Cellular viability of PSS/DOXO/PLL/HA-coated (black GNRs (blue $\boldsymbol{\Delta}$ ) and free DOXO (green $\boldsymbol{\nabla})$ in $(\mathrm{a}, \mathrm{b}) \mathrm{HeLa}$ and $(\mathrm{c}, \mathrm{d})$

, (PSS/DOXO/PLL) $2 /$ HA-coated (red -), and PSS/PLL/HA-coated MDA-MB-231 cells after 24 and $48 \mathrm{~h}$ of incubation.

HA-coated GNRs for $6 \mathrm{~h}$ (see Figure S2 in Supporting Information).

On the other hand, at longer incubation times $(>6 \mathrm{~h})$, DOXO released from particles reached the cell nuclei and its fluorescence became more important than that of free DOXO, particularly after $24 \mathrm{~h}$ of incubation (see Figure S3 in Supporting Information). This was especially noted for PSS/ DOXO/PLL/HA-coated GNRs; for (PSS/DOXO/PLL) $/$ HA-coated ones, the observed intensity was slightly lower, in agreement with their more sustained release pattern, as observed previously (see Figure 3). Nonetheless, the presence of DOXO in the cell cytoplasms at $24 \mathrm{~h}$ for both types of hybrid nanoplatforms confirmed the sustained DOXO release from the nanoconstructs.

Fluorescence images of cancerous cells with internalized DOXO-loaded nanohybrids under laser light irradiation suggested that NIR light exposure enhanced particle uptake and drug release by modulating the electrostatic interactions between DOXO and the polymeric layers. ${ }^{56}$ The presence of DOXO in cell nuclei was observed faster under laser exposure, as noted by the stronger red signals in nuclei at shorter incubation times $(6 \mathrm{~h})$ and which was maintained at longer times. No important differences in fluorescence signals between PSS/DOXO/PLL/HA-coated and (PSS/DOXO/ $\mathrm{PLL})_{2}$ /HA-coated GNRs after $24 \mathrm{~h}$ of incubation under NIR irradiation were observed. Here, it is necessary to bear in mind that (PSS/DOXO/PLL/HA-coated and (PSS/DOXO/PLL) 2 / HA-coated GNRs released ca. 40 and $25 \%$ of the total drug at $24 \mathrm{~h}$, respectively, but the bilayered nanohybrid is able to encapsulate more drug; thus, the DOXO concentration administered to cells under irradiation should be relatively similar in both cases.
2.5. In Vitro Cell Cytotoxicity of DOXO-Loaded GNRs. The cytotoxicity of the two different DOXO-loaded GNRs was assessed by means of the CCK- 8 proliferation assay. Incubation of free DOXO, PSS/DOXO/PLL/HA-coated GNRs, (PSS/DOXO/PLL) $2 / \mathrm{HA}$-coated GNRs, and PSS/ PLL/HA-coated GNRs (control) was done for 24 and $48 \mathrm{~h}$ in cervical HeLa and breast MDA-MB-231 tumoral cell lines at different NP concentrations (see also Table S1 in Supporting Information).

Control PSS/PLL/HA-coated GNRs were observed to be safe and nontoxic, with cell viabilities above $95 \%$ for MDAMB-231 cells at 24 and $48 \mathrm{~h}$ and HeLa ones at $24 \mathrm{~h}$ (Figure $6 \mathrm{a}, \mathrm{c}, \mathrm{d})$ at concentrations up to $2.5 \times 10^{10} \mathrm{NP} / \mathrm{mL}$. At larger particle concentrations, cell viabilities decrease but were still above $50 \%$, an accepted limit to consider a material as biocompatible. For HeLa cells after $48 \mathrm{~h}$ of incubation (Figure $6 \mathrm{~b})$, cell viability hardly remained above $50 \%$ at the most diluted concentrations (below $2.5 \times 10^{10} \mathrm{NP} / \mathrm{mL}$ ). ${ }^{35}$ This larger cell toxicity would be related to a larger particle uptake mediated by a receptor-endocytosis process, in which CD44 receptors largely overexpressed on the membrane surfaces of HeLa cells would interact with the HA coating of the hybrid NPs, which might compromise cell function and viability (see Figure S4 in Supporting Information). ${ }^{35,57}$ On the other hand, DOXO-loaded GNRs exhibited a stronger cell toxicity, which can be ascribed exclusively to the drug action. Specifically, $\mathrm{PSS} / \mathrm{DOXO} / \mathrm{PLL} / \mathrm{HA}$-coated GNRs and (PSS/DOXO/ $\mathrm{PLL})_{2}$ /HA-coated ones (Figure 6a,b) exhibited similar concentration-dependent toxicity profiles in HeLa cells, with the former nanoconstructs being more toxic in agreement with their observed faster drug release rates (see Figure 3). In addition, survival cell rates in the presence of DOXO-loaded hybrid particles were smaller than those for the free drug, 
suggesting that a sustained drug release pattern from the NPs is much more effective for a therapeutic action, that is, similar cell toxicities can be achieved using much lower drug concentrations (Table 2).

Table 2. IC $_{50}$ Values for Free DOXO, PSS/DOXO/PLL/ HA-Coated and (PSS/DOXO/PLL) 2 /HA-Coated GNRs in HeLa, and MDA-MB-231 Cell Lines at 24 and $48 h^{a}$

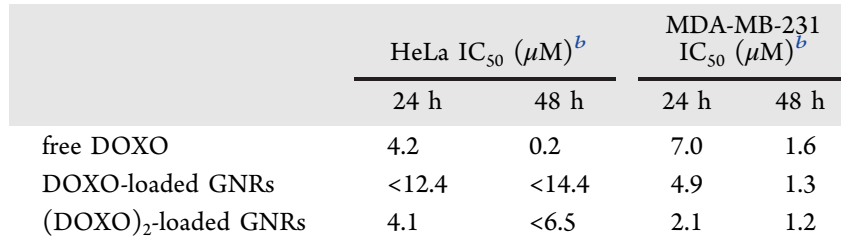

${ }^{a}$ Uncertainties are estimated to be less than $10 \% .{ }^{b} \mathrm{IC}_{50}$ concentrations obtained from DOXO-loaded GNRs and (DOXO) ${ }_{2}$-loaded GNRs were calculated taking into account the percentage of drug released at 24 or $48 \mathrm{~h}$ (see Figure 3).

On the other hand, MDA-MB-231 cells seemed to be less sensitive to DOXO at 24 and $48 \mathrm{~h}$ as suggested by the larger $\mathrm{IC}_{50}$ values compared to those of HeLa cells. At low NP concentrations (below $2.5 \times 10^{10} \mathrm{NP} / \mathrm{mL}$ ), similar concentration-dependent toxicity profiles were observed for both nanocarriers and the free drug. At higher NP concentrations, PSS/DOXO/PLL/HA-coated GNRs again displayed larger cell toxicities, as observed for HeLa cells.
2.6. In Vitro Potential Combined Effects of Chemoand Photothermal Therapies. To analyze the combinatorial effect of PPTT and DOXO, CCK-8 viability assays were also carried out in the presence of NIR light illumination. Free DOXO and PSS/DOXO/PLL/HA-coated, (PSS/DOXO/ $\mathrm{PLL})_{2} / \mathrm{HA}$-coated, and PSS/PLL/HA-coated GNRs (as control) were administered to HeLa and MDA-MB-231 cells in the presence of NIR laser illumination $(808 \mathrm{~nm})$ at different intensities $\left(0.5,1,3 \mathrm{~W} / \mathrm{cm}^{2}\right)$ after $6 \mathrm{~h}$ of incubation for $5 \mathrm{~min}$, and the cell viabilities were analyzed after 24 and $48 \mathrm{~h}$ of incubation (Figure 7). The NP concentration was set up at 2.5 $\times 10^{10} \mathrm{NP} / \mathrm{mL}$

First, it was noted that cell toxicity induced by free DOXO slightly increases as the irradiation intensity does after $24 \mathrm{~h}$. This effect was related to small macroscopic temperature increases under NIR light illumination (see Figure S5 in Supporting Information), which would promote more efficient drug diffusion inside cells by increasing tissue permeability and sensitivity to the drug therapeutic action. ${ }^{58}$ At longer incubation times, these changes were largely diminished as a consequence of the saturation of the cytostatic activity of the chemotherapeutic drug.

As shown previously, bare PSS/PLL/HA-coated GNRs were completely nontoxic in the absence of NIR irradiation at the selected concentration. In comparison, NIR laser illumination of these NPs led to a noticeable increase in cell toxicity because of local temperature increments generated by the plasmonic hyperthermic effect (see Figure S5). ${ }^{59}$ Also, HeLa cells exhibited lower cell viabilities than MDA-MB-231 ones as
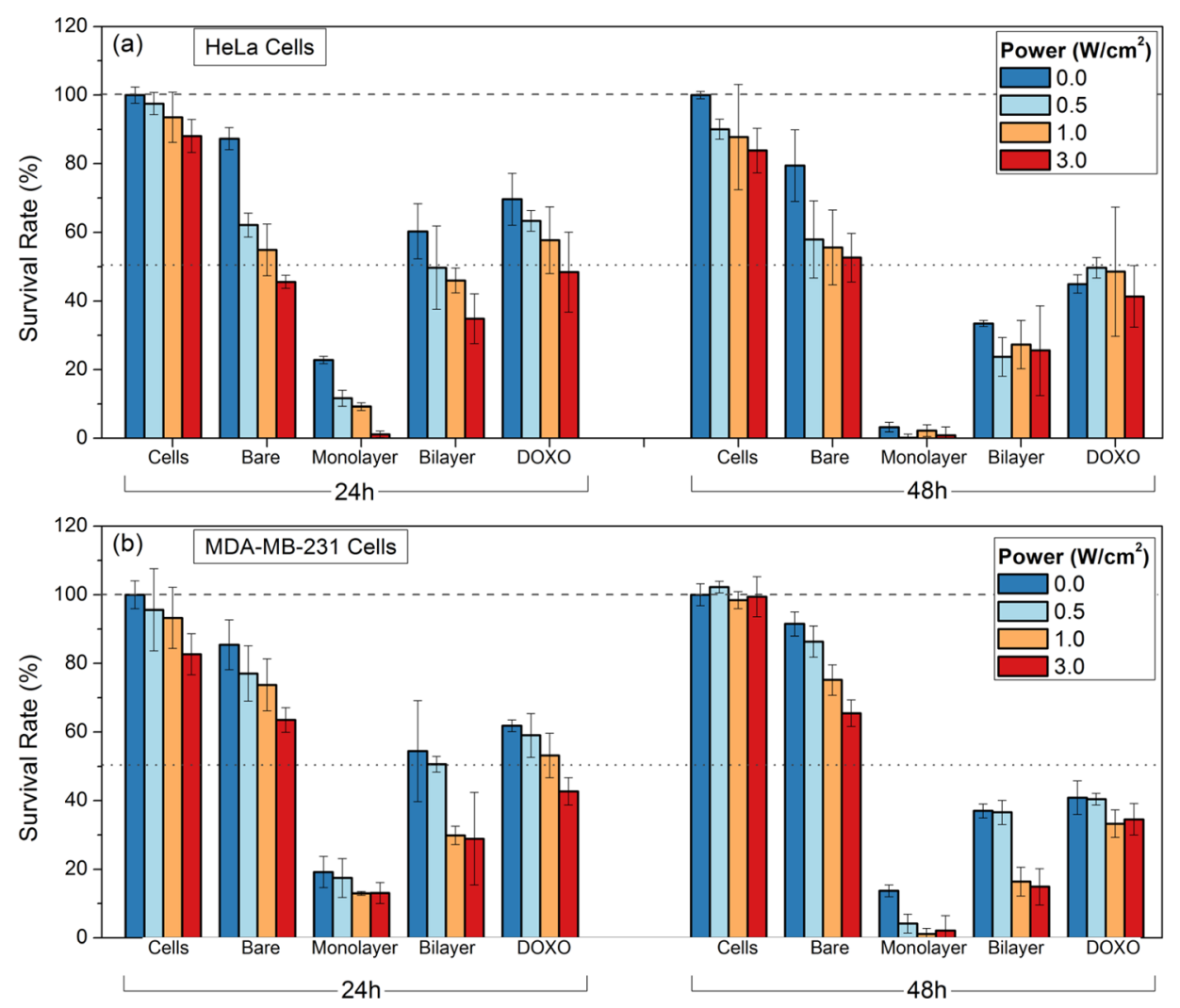

Figure 7. Photothermal-induced toxicity of PSS/PLL/HA-coated (bare), PSS/DOXO/PLL/HA-coated (monolayer), and (PSS/DOXO/PLL) 2 / HA-coated (bilayer) GNRs and free DOXO (DOXO) in (a) HeLa and (b) MDA-MB-231 cells. The cells were irradiated with a continuous-wave (CW) laser at $808 \mathrm{~nm}$ at 0 (blue), 0.5 (light blue), 1 (light red), and $3 \mathrm{~W} / \mathrm{cm}^{2}$ (red) for $5 \mathrm{~min}$. The dotted (50\%) and dashed lines (100\%) are only to guide the eye. 

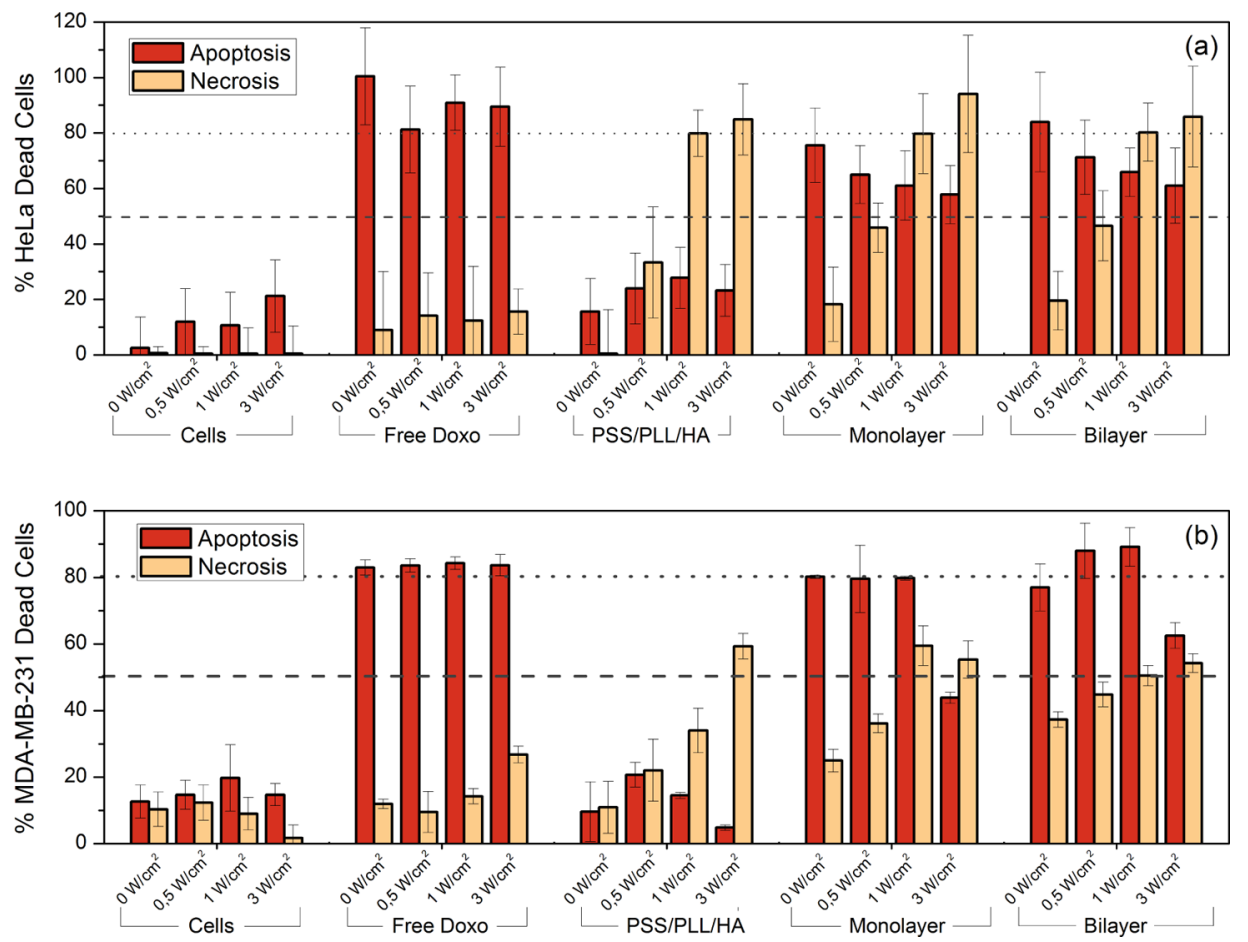

Figure 8. Ann V/7AAD death cell assay in (a) HeLa and (b) MDA-MB-231 cells. The percentage of cells displaying Annexin V fluorescence is shown in dark orange, and the percentage of necrotic ones stained with 7-ADD is shown in light orange. PSS/DOXO/PLL/HA-coated (monolayer), (PSS/DOXO/PLL) 2 /HA-coated (bilayer), and PSS/PLL/HA-coated GNRs were irradiated at several power intensities with a CW NIR laser $(808 \mathrm{~nm})$. DOXO was used as a positive control for apoptotic cells. The untreated cells were used as a negative control. The dotted and dashed lines are only to guide the eye.

a result of their larger particle uptakes as a consequence of the larger overexpression of the HA receptor of the former type of cells, as mentioned above.

Both PSS/DOXO/PLL/HA-coated and (PSS/DOXO/ $\mathrm{PLL})_{2} / \mathrm{HA}$-coated GNRs gave rise to NIR light intensitydependent cell toxicities, these being larger than those in the absence of light illumination. This highlights a potential synergetic effect between PPTT and chemotherapy, for example, increments in cell toxicity from $80 \%$ to almost $100 \%$ for PSS/DOXO/PLL/HA-coated NPs and from 62 to $83 \%$ for $(\mathrm{PSS} / \mathrm{DOXO} / \mathrm{PLL})_{2} / \mathrm{HA}$-coated nanocarriers at $3 \mathrm{~W} /$ $\mathrm{cm}^{2}$ in HeLa cells after $48 \mathrm{~h}$ of incubation. Despite the evident influence of light, PSS/DOXO/PLL/HA-coated GNRs displayed again a faster toxic activity compared to (PSS/DOXO/ $\mathrm{PLL})_{2}$ /HA-coated ones as a consequence of their quicker cargo release. Besides, the attenuated light absorption observed in (PSS/DOXO/PLL) $)_{2} / \mathrm{HA}$-coated GNRs by the presence of a thicker polymeric shell would additionally screen both drug release and light-to-heat conversion, contributing to their lower cell cytotoxicities.

2.7. Cell Death. To determine by which pathway (either necrosis or apoptosis) the present multifunctional nanoplatforms cause toxicity to cells, an Annexin V (AnnV)/7Aminoactinomycin D (7AAD) dead cell assay was performed. AnnV is a protein that specifically binds to phosphatidyl serine, a phospholipid that becomes exposed on the cell surface as a result of apoptosis. 7AAD, on the other hand, is a fluorophore that intercalates with DNA and is used to analyze loss of membrane integrity during necrosis. HeLa and MDA-MB-231 cells were treated with PSS/DOXO/PLL/HA-coated, (PSS/ $\mathrm{DOXO} / \mathrm{PLL})_{2} / \mathrm{HA}$-coated, and PSS/PLL/HA-coated GNRs and free DOXO used as a positive control for apoptosis.
Untreated cells were the negative (live) control. After $6 \mathrm{~h}$ of incubation with the hybrid NPs or the free drug, cells were illuminated with a CW NIR laser light at several power intensities $\left(0,0.5,1\right.$, and $\left.3 \mathrm{~W} / \mathrm{cm}^{2}\right)$ for $5 \mathrm{~min}$. The proportion of live, dead, and apoptotic cells was quantified by flow cytometry after $24 \mathrm{~h}$ of incubation. Here, it is considered that necrosis and apoptosis are different mechanisms of cell death, according to Kerr et al, ${ }^{60}$ so both processes can be present simultaneously, that is, 7-ADD fluorescence will only appear when the membrane is disrupted and the Annexin $\mathrm{V}$ signal will be always present in apoptotic cells. We did not focus on the molecular mechanisms involved in the observed processes, which will be the subject of a future study.

Cell death in free DOXO-treated cells was dominated by apoptosis (ranging from 80 to $90 \%$ ) both in the absence and presence of NIR laser irradiation (Figure 8), denoting that irradiation does not have an influence on the DOXO-induced cell mechanism. A much smaller signal from 7-ADD was also noted, but the percentage of gathered cells was always below ca. $10-15 \%$, which may be associated to secondary necrosis, that is, the loss of membrane integrity by late apoptotic cells. ${ }^{61}$ Thus, it can be safely considered that the action of the chemodrug is mainly through apoptosis. On the other hand, PSS/PLL/HA-coated GNR-induced cell death in the absence of light irradiation was similar as that of control cells, corroborating their low toxicity. In the presence of NIR irradiation and as the light fluency is increased, the extent of necrotic cells was largely enhanced as a consequence of the photothermal effect, especially at fluencies above $1 \mathrm{~W} / \mathrm{cm}^{2}$ (under $5 \mathrm{~min}$ of illumination), which is characterized by extensive membrane blebbing, budding, and endosome expansion (see below). Similar necrotic-induced cell death 
was also previously noted for other NIR-irradiated GNR-based nanosystems for PPTT applications. ${ }^{62,63}$ Conversely, very recently, NIR illumination for short times (2-4 min) of gold nanoplates using a $1064 \mathrm{~nm}$ laser light was shown to induce cell death by apoptosis, which is mediated by nuclear encoded proteins Bak and Bax through the activation of the BH3-only protein BID. ${ }^{61}$ Hence, it can be considered that the type of predominant programmed cell death mechanism may depend on different inter-related factors such as the illumination conditions, cellular internalization and location, particle type and concentration, and so forth.

In addition, experimental data confirmed that cell death caused by PSS/DOXO/PLL/HA-coated and (PSS/DOXO/ $\mathrm{PLL})_{2} / \mathrm{HA}$-coated GNRs in the absence of NIR irradiation is mainly driven through apoptosis thanks to the chemodrug action. As NIR irradiation is applied and the fluency progressively increased, cell apoptotic-induced mortalities (generally between ca. $60-80 \%$ for HeLa and ca. $80-90 \%$ for MDA-MB-231 cells up to $1 \mathrm{~W} / \mathrm{cm}^{2}$ ) are also observed as occurred, for example, for Au nanoshells, ${ }^{64}$ and necrosis is progressively enhanced and added to the apoptotic effect of DOXO.

From Figure 8, it can be also appreciated that the level of necrotic cells in HeLa cells was higher than that in MDA-MB231 ones. For instance, at $3 \mathrm{~W} / \mathrm{cm}^{2}$, HeLa cells exhibited a 7ADD fluorescence of ca. at $80 \%$ compared to ca. $60 \%$ for MDA-MB-231 cells. This was probably a consequence of the larger particle uptake by the former cell line, as mentioned before: a larger GNR concentration into cells would lead to higher temperatures and then to cell death through a necrotic pathway.

The type of induced cell death and the confirmation of cell particle internalization were also monitored by TEM imaging. PSS/PLL/HA-coated and PSS/DOXO/PLL/HA-coated GNRs were incubated in HeLa cells for $6 \mathrm{~h}$ at standard conditions. Some cells were also irradiated with an $808 \mathrm{~nm}$ $\mathrm{CW}$ laser for $5 \mathrm{~min}$ at $1 \mathrm{~W} / \mathrm{cm}^{2}$.

PSS/PLL/HA-coated GNRs were observed to internalize inside HeLa cells without any sign of associated cell toxicity (see Figure S6a,b in Supporting Information). These particles were located at the cell cytoplasm inside endosomal vesicles, which agrees with a receptor-mediated endocytosis process promoted by the binding between HA and membrane surfaceexpressed CD44 receptors. Some membrane blebs related to the dehydration process undergone by cells during sample preparation were also observed, and neither shrinking nor cell swelling was noted. In comparison, internalization of PSS/ DOXO/PLL/HA-coated GNRs was accompanied by budding and cellular separation in apoptotic bodies (see Figure S6c,d in Supporting Information) related to the beginning of an apoptotic process associated to the DOXO chemotherapeutic activity, further corroborating the flow cytometry data. The hybrid particles were also observed inside vesicles, and some membrane blebs were noted, as occurred for PSS/PLL/HAcoated particles.

Conversely, when PSS/PLL/HA-coated GNRs were internalized inside HeLa cells and irradiated at a fluency of $1 \mathrm{~W} /$ $\mathrm{cm}^{2}$ for $5 \mathrm{~min}$, mitochondrial swelling and more membrane blebs, characteristic of a necrotic process were observed ${ }^{65}$ in agreement with the Annexin V/7AAD dead Cell assay (Figure $9 \mathrm{a}, \mathrm{b})$. The hybrid particles were localized inside vesicles and their morphology appeared altered, that is, some of them partially lost their typical cylindrical morphology to become

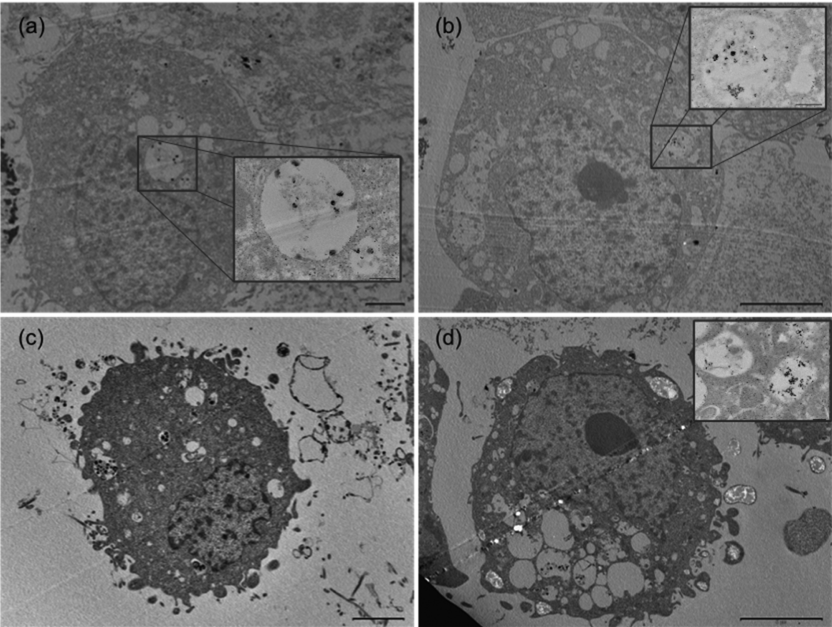

Figure 9. TEM images of HeLa cells after $6 \mathrm{~h}$ of incubation with $(\mathrm{a}, \mathrm{b})$ PSS/PLL/HA-coated GNRs and (c,d) (PSS/DOXO/PLL) $2 / \mathrm{HA}-$ coated GNRs under irradiation with an $808 \mathrm{~nm} \mathrm{CW}$ laser for 5 min at $1 \mathrm{~W} / \mathrm{cm}^{2}$. Scale bars are $2 \mu \mathrm{m}$.

more spherical as a consequence of melting due to the relatively high temperatures reached under laser exposure. ${ }^{65}$ These particle-loaded vesicles have larger sizes than those observed in nonirradiated cells, probably associated to an increase in the inner pressure upon light-induced heating. No evident signs of budding, shrinking, or presence of apoptotic bodies were observed.

Finally, the combination of DOXO and PPTT after PSS/ DOXO/PLL/HA-coated GNRs internalization and subsequent NIR irradiation involved simultaneous signs of both apoptosis and necrosis in cells such as the observation of cell dehydration (shrinkage), budding, and the presence of apoptotic bodies and blebs inside and around cell membranes corresponding to the chemotherapeutic activity of DOXO and PPTT effect, respectively, which is also in agreement with the Annexin V/7AAD dead data (Figure 9c,d.). Most part of the observed particle-containing vesicles appeared expanded with some melted GNRs present inside.

\section{CONCLUSIONS}

In this work, we successfully designed and obtained GNRbased hybrid nanoplatforms as a potential tool for the controlled delivery of the therapeutic cargo by different internal and external triggers and to get potential combined chemo- and photothermal therapeutic outcomes by making use of the photothermal activity provided by the metal NPs under NIR light illumination and the presence of a chemotherapeutic agent (DOXO) assembled in the particle polymeric coating layer. In this manner, GNRs were surface-functionalized with PSS, PLL, DOXO, and HA by means of the LbL assembly technique. HA was used as the final outer coating layer to provide particle colloidal stabilization as well as to serve as a targeting moiety to bind CD44 receptors overexpressed on the surface of different types of cancerous cells. Single and dual DOXO layers could be formed within the surface-assembled PE layers of GNRs (PSS/PLL/DOXO/HA-coated and (PSS/ $\mathrm{PLL} / \mathrm{DOXO})_{2}$ /HA-coated GNRs, respectively). Drug release from the hybrid particles could be either enzymatically and/or light-triggered thanks to the biodegradability of PLL in the presence of proteases and the modulation of interactions in the $\mathrm{PE}$ coating layer by light, respectively. In vitro microscopy 
fluorescence and TEM imaging confirmed the successful cell internalization of the hybrid nanoplatforms. The simultaneous combination of chemotherapy and photothermal activity within this single nanoplatform increased cell cytotoxicity significantly. This fact might potentially help to overcome drug resistances to chemotherapeutic agents by allowing the use of much lower drug concentrations. Moreover, it was noted that HA-ligand targeting enhanced the photothermal effect as a result of NP accumulation in cells to greater extents. The type of cell death mechanism was evaluated by the Annexin V/ $7 \mathrm{AAD}$ dead cell assay and TEM. It was noted that PPTT caused necrosis to cells, as observed by mitochondrial swelling and membrane blebs by TEM, whilst DOXO activated apoptosis. The present GNR-based nanohybrids might additionally be optimized for other multimodal cancer therapies, and their optical properties might be exploited for therapy monitorization and preliminary diagnosis, making these nanosystems ideal nanomaterials for theranosis.

\section{EXPERIMENTAL SECTION}

4.1. Materials. $\mathrm{CTAB}$ for molecular biology, tetrachloroauric acid $\left(\mathrm{HAuCl}_{4} \cdot 3 \mathrm{H}_{2} \mathrm{O}\right)$, silver nitrate $\left(\mathrm{AgNO}_{3}\right)$, sodium borohydride $\left(\mathrm{NaBH}_{4}\right)$, PSS, PLL, HA, and trypsin $(0.25 \times)$ were purchased from Sigma-Aldrich. Ascorbic acid was purchased from Fluka. DOXO hydrochloride was purchased from Calbiochem. All other reagents were of analytical grade and/or suitable for cell culture, as corresponding. All chemicals were used as received.

4.2. Synthesis of GNRs. GNRs were synthesized using a seed-mediated growth method. First, CTAB-capped Au seeds were obtained. To do that, $7.5 \mathrm{~mL}$ of a $0.2 \mathrm{M} \mathrm{CTAB}$ solution was gently mixed with $0.25 \mathrm{~mL}$ of $0.01 \mathrm{M} \mathrm{HAuCl}_{4}$ in a water bath at $27{ }^{\circ} \mathrm{C}$. Next, a $0.01 \mathrm{M} \mathrm{NaBH}_{4}$ solution was prepared in ice-cold water. This solution was left to rest for $2-3 \mathrm{~min}$ to ensure a good dispersion of the reductant. Afterward, $0.6 \mathrm{~mL}$ of ice-cold $0.01 \mathrm{M} \mathrm{NaBH}_{4}$ was added to the $\mathrm{Au}-\mathrm{CTAB}$ solution under stirring at $200 \mathrm{rpm}$ in one pull, after which the mixed solution turned brownish yellow. This was mixed gently by hand for $2 \mathrm{~min}$ and then left undisturbed in a water bath at $27{ }^{\circ} \mathrm{C}$ for $1 \mathrm{~h}$ to allow the excess sodium borohydride to be decomposed.

For the growth of GNRs, $425 \mu \mathrm{L}$ of a $0.01 \mathrm{M} \mathrm{HAuCl}_{4}$ solution was added to $10 \mathrm{~mL}$ of $0.2 \mathrm{M} \mathrm{CTAB}$ in a water bath at $27{ }^{\circ} \mathrm{C}$, after which the solution turned yellow bright while stirred at $500 \mathrm{rpm}$. Then, a $0.01 \mathrm{M}$ a $\mathrm{AgNO}_{3}$ solution was prepared in the dark. Different volumes of the silver solution (ranging from 63 to $143 \mu \mathrm{L}$ ) were added to the Au growth solution followed by gentle mixing by hand. Then, $68 \mu \mathrm{L}$ of a $0.1 \mathrm{M}$ ascorbic acid solution was added followed by gentle stirring at $500 \mathrm{rpm}$ until the solution turned colorless and left it in this way for $4 \mathrm{~min}$ in a water bath at $27^{\circ} \mathrm{C}$. Finally, $110 \mu \mathrm{L}$ of the $\mathrm{Au}$ seed solution was gently added to the Au growth solution while stirring for $2 \mathrm{~min}$ and then stopped. The resulting solution was left undisturbed in a water bath overnight at $27{ }^{\circ} \mathrm{C}$, and the solution turned reddish pink. The formed GNRs were centrifuged at least twice at $27^{\circ} \mathrm{C}$ for $20 \mathrm{~min}$ and resuspended in $10 \mathrm{~mL}$ of deionized water. The UV-visible absorption spectra of the obtained GNRs were measured using a Cary Bio $100 \mathrm{UV}-$ Vis spectrophotometer (Agilent Technologies, USA). The sizes and aspect ratios of GNRs were measured using a JEOL JEM 1011 (Japan) TEM microscope operating at an accelerating voltage of $120 \mathrm{kV}$.
4.3. Preparation of PE Multilayers onto GNRs. 4.3.1. PSS/DOXO/PLL/HA-Coated GNRs. Using the LbL method, multilayers of PSS, DOXO, PLL, and HA were successfully deposited on the GNR surfaces. For PSS coating, a solution of PSS $(10 \mathrm{mg} / \mathrm{mL})$ in $12 \mathrm{mM} \mathrm{NaCl}$ was prepared. When this PE was completely dissolved, $1 \mathrm{~mL}$ of this PE solution was mixed with $1 \mathrm{~mL}$ of a $12 \mathrm{mM} \mathrm{NaCl}$ solution, and the resulting mixture was stirred at $500 \mathrm{rpm}$. Then, the latter solution was added dropwise to $1 \mathrm{~mL}$ of a GNR solution (OD $\approx 1$ ) while stirring. After $1 \mathrm{~h}$ of adsorption, the mixture was centrifuged twice at $15000 \mathrm{rpm}$ for $20 \mathrm{~min}$ and resuspended in $1 \mathrm{~mL}$ of Milli-Q water. Next, a solution of DOXO $(1 \mathrm{mM})$ was prepared in an acetic acid buffer at $\mathrm{pH} 4.1^{66}$ to protonate the drug amino groups for a more efficient $\mathrm{LbL}$ electrostatic-based deposition. DOXO (typically $100 \mu \mathrm{g}$ ) was diluted in $700 \mu \mathrm{L}$ of water and stirred at $500 \mathrm{rpm}$ for $5 \mathrm{~min}$. Next, $1 \mathrm{~mL}$ of the PSScoated GNRs was added dropwise to the DOXO solution under stirring. After $1 \mathrm{~h}$, the mixture was centrifuged once at $15000 \mathrm{rpm}$ for $20 \mathrm{~min}$ and redispersed in $1 \mathrm{~mL}$ of Milli-Q water. As the PSS/DOXO-coated GNR particles have a negative surface charge, a subsequent cationic PLL layer can be used to coat the hybrids. Thus, $100 \mu \mathrm{L}$ of a PLL solution (5 $\mathrm{mg} / \mathrm{mL}$ ) was added to $1 \mathrm{~mL}$ of Milli-Q water and stirred for 5 min. Then, $1 \mathrm{~mL}$ of PSS/DOXO-coated GNRs was added dropwise. After $1 \mathrm{~h}$, the NPs were centrifuged at $15000 \mathrm{rpm}$ for $15 \mathrm{~min}$ and resuspended in $1 \mathrm{~mL}$ of Milli-Q water. The deposition of the final HA layer was made by preparing $60 \mu \mathrm{L}$ of a HA concentrated solution $(1 \mathrm{mg} / \mathrm{mL})$, which was mixed with $1 \mathrm{~mL}$ of Milli-Q water and stirred at $500 \mathrm{rpm}$ for 5-10 min. The former PSS/DOXO/PLL-coated GNRs were added dropwise to the former HA solution. After $1 \mathrm{~h}$, the final coated GNRs were centrifuged at $15000 \mathrm{rpm}$ for $10 \mathrm{~min}$ and redispersed in $1 \mathrm{~mL}$ of Milli-Q water.

4.3.2. (PSS/DOXO/PLL) $2 / H A$-Coated GNRs. For these particles, the first three layers corresponding to PSS, DOXO, and PLL were obtained as previously explained. Next, a second new PSS layer was formed by mixing $250 \mu \mathrm{L}$ of the PSS solution with $750 \mu \mathrm{L}$ of $12 \mathrm{mM} \mathrm{NaCl}$ and stirring at $500 \mathrm{rpm}$. Then, $1 \mathrm{~mL}$ of PSS/DOXO/PLL-coated GNRs $(\mathrm{OD} \approx 1)$ was added dropwise while stirring. After $1 \mathrm{~h}$, the mixed solution was centrifuged once at $15000 \mathrm{rpm}$ for $20 \mathrm{~min}$ and redispersed in $1 \mathrm{~mL}$ of Milli-Q water. Next, $100 \mu \mathrm{g}$ of DOXO $(1 \mathrm{mM})$ was mixed with $1 \mathrm{~mL}$ of acetic acid buffer and stirred at $500 \mathrm{rpm}$ for $5 \mathrm{~min}$. (PSS) $2 / \mathrm{DOXO} / \mathrm{PLL}$-coated GNRs were added to this solution dropwise under stirring. After $1 \mathrm{~h}$, the mixture was centrifuged once at $15000 \mathrm{rpm}$ for $20 \mathrm{~min}$ and redispersed in 1 $\mathrm{mL}$ of water. Then, $50 \mu \mathrm{L}$ of a $5 \mathrm{mg} / \mathrm{mL}$ PLL solution was mixed with $1 \mathrm{~mL}$ of water and stirred at $500 \mathrm{rpm}$ for $5 \mathrm{~min}$. Again, $1 \mathrm{~mL}$ of (PSS/DOXO) 2 /PLL-coated GNRs was added to this PLL solution dropwise under stirring. After $1 \mathrm{~h}$, the mixture was centrifuged once at $15000 \mathrm{rpm}$ for $20 \mathrm{~min}$ and redispersed in $1 \mathrm{~mL}$ of MilliQ water. The final HA layer implied the dilution of $60 \mu \mathrm{L}$ of $\mathrm{HA}$ in $1 \mathrm{~mL}$ of water and stirred at $500 \mathrm{rpm}$ for 5-10 $\mathrm{min}$. (PSS/DOXO/PLL/) $)_{2}$-coated GNRs were then added drop by drop at $500 \mathrm{rpm}$. After $1 \mathrm{~h}$, the final hybrid NPs were centrifuged at $15000 \mathrm{rpm}$ for $10 \mathrm{~min}$ and redispersed in $1 \mathrm{~mL}$ of deionized Milli-Q water.

4.4. Dynamic Light Scattering. DLS measurements were performed using an ALV-5000 digital correlator system (ALV $5000 / \mathrm{E}, \mathrm{ALV} \mathrm{GmbH}$, Germany) equipped with a temperature controller set at $25 \pm 0.1{ }^{\circ} \mathrm{C}$. The scattered light was vertically polarized with a $488 \mathrm{~nm}$ solid-state laser $(2 \mathrm{~W})$. The hydrodynamic radius, $R_{\mathrm{H}}$, was obtained for diluted samples 
from DLS measurements at an incidence angle of $90^{\circ}$ by analysis of the DLS data by means of the CONTIN algorithm developed by Provencher ${ }^{67}$ and the Stokes-Einstein equation, $R_{\mathrm{H}}=k_{\mathrm{B}} T / 6 \pi \eta D$, where $k_{\mathrm{B}}$ is the Boltzmann constant, $T$ is the temperature, $\eta$ is the solution viscosity, and $D$ is the diffusion coefficient of the particles. Measurements were performed at least in triplicate with a sampling time of $60 \mathrm{~s}$ each and averaged.

4.5. Electrophoretic Mobilities. $\zeta$-Potentials of bare and PE-coated GNRs were measured using Nano ZS (Nanoseries, Malvern Instruments, UK). The instrument measures the electrophoretic mobility of the particles and converts it into $\zeta$ potential data using the classical Smoluchowski equation

$$
\alpha=\varepsilon \frac{\zeta}{\eta}
$$

where $\alpha, \varepsilon, \zeta$, and $\eta$ denote the electrophoretic mobility, permittivity of the medium, $\zeta$-potential of the particles, and viscosity, respectively. Each sample was fed into a folded capillary, clear, disposable cell. Measurements were initiated after thermal equilibration at $25{ }^{\circ} \mathrm{C}$. The number of runs was automatically determined by the software, and measurements were performed in triplicate. The results were reported as the mean \pm SD.

4.6. Quantitative Analysis of DOXO Loading. To determine the EE and LC of DOXO within PSS/PLL/DOXO/ HA-coated and (PSS/PLL/siRNA) $2 /$ HA-coated GNRs, the hybrid NPs were centrifuged at $15000 \mathrm{rpm}$ at $20{ }^{\circ} \mathrm{C}$ for 20 min. The DOXO content in the supernatant was measured by means of UV-vis and fluorescent spectroscopies. Previously, a calibration curve with free DOXO was obtained, and the absorbance/fluorescence of supernatants of bare GNR solutions was also considered as an additional blank. UV-vis measurements were made at $488 \mathrm{~nm}$. The fluorescence standard curves were set at $\lambda_{\mathrm{ex}}=480 \mathrm{~nm}$ and collected at $\lambda_{\text {em }}=560-590 \mathrm{~nm}$. UV-vis spectra were measured in a Cary Bio $100 \mathrm{UV}$-vis spectrophotometer (Agilent Technologies, USA). Fluorescence spectra were monitored in a Cary Eclipse spectrophotometer (Agilent Technologies, USA). Each sample was measured in triplicate for three different batches. The EE and LC were calculated by the following expressions

$$
\begin{aligned}
\mathrm{EE}(\%)= & \frac{\text { total amount of DOXO feeded }- \text { DOXO in supernatant }}{\text { total amount of DOXO feeded }} \\
& \times 100 \\
\mathrm{LC}(\%)= & \frac{\text { total amount of DOXO feeded }- \text { DOXO in supernatant }}{\text { total weight of nanoparticles }} \\
& \times 100
\end{aligned}
$$

4.7. Inductively Coupled Plasma Mass Spectrometry. The Au concentration in solution or in cells was determined by inductively coupling plasma mass spectrometry in a Varian 820-MS equipment (Agilent Technologies, USA). One milliliter of $1 \times 10^{11} \mathrm{GNRs} / \mathrm{mL}$ (or 100000 cells with NPs where corresponding) was dissolved in $0.3 \mathrm{~mL}$ of $\mathrm{HCl}[37 \%$ $(\mathrm{v} / \mathrm{v})]$ and $0.1 \mathrm{~mL}$ of $\mathrm{HNO}_{3}[70 \%(\mathrm{v} / \mathrm{v})]$. The solutions were diluted with deionized water until reaching a final volume of 2 $\mathrm{mL}$. The intensity of the emission wavelength was measured and compared to a standard solution.

4.8. In Vitro Release Experiments. DOXO cumulative release profiles from the hybrid NPs were measured in vitro at a constant temperature of $37^{\circ} \mathrm{C}$ at $300 \mathrm{rpm}$ magnetic stirring for several days at $\mathrm{pHs} 7.4$ and 5.5. To obtain the release profiles, $1 \mathrm{~mL}$ of hybrid GNRs was placed into dialysis tubes (SpectraPore, MWCO 3500) and immersed into $50 \mathrm{~mL}$ of buffer supplemented with $10 \%(\mathrm{v} / \mathrm{v}) \mathrm{FBS}$ at the $\mathrm{pH}$ of interest. The released DOXO concentration was determined at different time intervals for each solution $\mathrm{pH}$. At each sampling time, 1 $\mathrm{mL}$ of the medium was withdrawn and replaced with the same volume of fresh buffer to maintain the required sink conditions. The DOXO content was measured by means of UV-vis and fluorescence using previously established calibration curves in the corresponding buffers. UV-vis spectra were measured in a Cary Bio 100 UV-vis spectrophotometer (Agilent Technologies, USA), and the fluorescence spectra were monitored in a Cary Eclipse spectrophotometer (Agilent Technologies, USA). Assays were carried out in triplicate.

4.8.1. Protease-Assisted DOXO Release. The enzymetriggered DOXO release from GNRs $\left(1 \mathrm{~mL}, 1 \times 10^{11} \mathrm{NP} /\right.$ $\mathrm{mL}$ ) was measured in vitro at a constant temperature of $37^{\circ} \mathrm{C}$ under moderate magnetic stirring $(300 \mathrm{rpm})$ for several days at pHs 7.4 and 5.5 in the presence and absence of trypsinethylenediaminetetraacetic acid ( $50 \mu \mathrm{L}$ per $40 \mathrm{~mL}$ of buffer). Hybrid GNRs $(1 \mathrm{~mL})$ were placed into dialysis tubes (SpectraPore, MWCO 3500) and immersed into $50 \mathrm{~mL}$ of buffer supplemented with $10 \%(\mathrm{v} / \mathrm{v})$ FBS and the suitable amount of trypsin at the $\mathrm{pH}$ of interest. The released DOXO concentrations were determined as explained above.

4.8.2. NIR Light-Triggered DOXO Release. To analyze the effect of the laser exposure on DOXO release from GNRs, 1 $\mathrm{mL}\left(1 \times 10^{11} \mathrm{NP} / \mathrm{mL}\right)$ of these hybrid NPs was incubated at $37^{\circ} \mathrm{C}$ under moderate stirring at $\mathrm{pH}$ 5.5. The experimental conditions were similar as those previously stated in the absence of trypsin, except for after 6 and $24 \mathrm{~h}$ of incubation GNRs, which were exposed to NIR light irradiation of 0.5 and $3 \mathrm{~W} / \mathrm{cm}^{2}$ for $5 \mathrm{~min}$. Irradiation was performed using a CW fiber-coupled diode laser source at $808 \mathrm{~nm}$ wavelength (50 W, Oclaro, Inc., San Jose, CA). The laser was powered by a Newport 5700-80 laser diode driver (Newport Corporation, Irvine, CA). A $200 \mu \mathrm{m}$ core optical fiber was used to transfer the laser power from the laser unit to the particle solution and connected with a lens telescope mounting accessory at the output, which allowed for fine-tuning the laser spot size in the range of $1-10 \mathrm{~mm}$. The output power was independently calibrated using an optical power meter (Newport 1916-C) and the laser spot size was previously measured with a laser beam profiler (Newport LBP-1-USB), which was placed at the same distance $(8 \mathrm{~cm})$ between the lens telescope output and the sampling cuvette.

4.9. Tumor Cells. Cervical HeLa and breast MDA-MB-231 cancer cells from Cell Biolabs (San Diego, CA) were grown at standard culture conditions $\left(5 \% \mathrm{CO}_{2}\right.$ at $\left.37^{\circ} \mathrm{C}\right)$ in Dulbecco's modified Eagle's medium (DMEM) supplemented with $10 \%$ (v/v) FBS, $2 \mathrm{mM}$ L-glutamine, 1\% (v/v) penicillin/ streptomycin, $1 \mathrm{mM}$ sodium pyruvate, and $0.1 \mathrm{mM}$ MEM nonessential amino acids.

4.10. Cellular Uptake by TEM. HeLa cells were seeded in 6-well plates $\left(2 \mathrm{~mL}, 5 \times 10^{4}\right.$ cells per well $)$ and grown for $24 \mathrm{~h}$ at standard culture conditions. Then, $200 \mu \mathrm{L}\left(2.5 \times 10^{10} \mathrm{NP} /\right.$ $\mathrm{mL}$ ) was added to cells. After $6 \mathrm{~h}$ of incubation, the NPcontaining cells were washed three times with phosphatebuffered saline (PBS), trypsinized, and centrifuged at $1500 \mathrm{rpm}$ for $4 \mathrm{~min}$. The cell pellets were fixed with $500 \mu \mathrm{L}$ of $2.5 \%$ (w/ v) glutaraldehyde and then included in an agar pellet, postfixed with osmium tetraoxide in $0.1 \mathrm{M}$ cacodylate buffer at $1 \%$ $(\mathrm{w} / \mathrm{v})$, and, finally, pelletized with Eponate (Ted Pella Inc, 
Redding, CA, USA). Ultrathin cuts were obtained with an ultramicrotome (UltraCut S, Leica Microsystems $\mathrm{GmbH}$ ) and analyzed with a TEM microscope (JEOL JEM 1011, Japan).

4.11. Cellular Uptake and DOXO Release by Fluorescence Microscopy. Particle uptake and DOXO release inside cells were also followed by fluorescence microscopy. HeLa cells were seeded on poly-L-lysine coated glass coverslips $\left(12 \times 12 \mathrm{~mm}^{2}\right.$, Sigma-Aldrich $)$ placed inside 6-well plates $(2 \times$ $10^{5}$ cells per well) with $2 \mathrm{~mL}$ of DMEM and grown for $24 \mathrm{~h}$ at standard culture conditions. Then, PSS/PLL/DOXO/HAcoated and (PSS/PLL/DOXO) $)_{2} /$ HA-coated GNRs $(2.5 \times$ $\left.10^{10} \mathrm{NP} / \mathrm{mL}, 250 \mu \mathrm{L}\right)$ were added to cells. After $6 \mathrm{~h}$ of incubation, the cells were washed three times with PBS and fresh medium was added. Next, some cells were irradiated with a CW $808 \mathrm{~nm}$ fiber-coupled diode laser source $(50 \mathrm{~W}$, Oclaro Inc., San Jose, CA) for $5 \mathrm{~min}$ at $0.5 \mathrm{~W} / \mathrm{cm}^{2}$. After the desired incubation time $(4,6,8,12$, and $24 \mathrm{~h})$, the cells were washed three times with PBS, fixed with $4 \%$ (w/v) paraformaldehyde for $10 \mathrm{~min}$, washed again with PBS, treated with Triton X-100 for $10 \mathrm{~min}$, and, finally, washed again with PBS. Then, the coverslips were mounted on glass slides, stained with DAPI (Invitrogen, USA) and cured for $24 \mathrm{~h}$ at $-20{ }^{\circ} \mathrm{C}$. The samples were visualized at $63 \times$ using a wide field fluorescence inverted microscope (Leica DMI6000B, Leica Microsystems, Germany) using the blue channel for DAPI $\left(\lambda_{\mathrm{ex}}=350 \mathrm{~nm}\right)$, the red channel for DOXO $\left(\lambda_{\mathrm{ex}}=520 \mathrm{~nm}\right)$, and transmitted light in differential interference contrast mode.

4.12. In Vitro Cell Cytotoxicity. The cytotoxicity of the present DOXO-loaded GNRs was tested in vitro by the CCK-8 proliferation assay. Cervical HeLa and breast MDA-MB-231 cancer cells at an optical confluence of $80-90 \%$ were seeded into 96-well plates $\left(100 \mu \mathrm{L}, 1.0 \times 10^{4}\right.$ cells/well $)$ and grown for $24 \mathrm{~h}$ at standard culture conditions in $100 \mu \mathrm{L}$ of the growth medium. After $24 \mathrm{~h}$ of incubation at $37{ }^{\circ} \mathrm{C}$ and $5 \% \mathrm{CO}_{2}, 100$ $\mu \mathrm{L}$ of a $2.5 \times 10^{10} \mathrm{NP} / \mathrm{mL}$ solution of PSS/PLL/DOXO/HAcoated and (PSS/PLL/DOXO) $2 /$ HA-coated GNRs were diluted in the corresponding cell culture medium and then injected into the wells and incubated for $6 \mathrm{~h}$. Free DOXO was used as a control at a molar concentration equivalent to the total drug loaded in PSS/PLL/DOXO/HA-coated GNRs. After the corresponding incubation period ( 24 or $48 \mathrm{~h}$ ), the culture medium was discarded, cells were washed with PBS $(\mathrm{pH} 7.4)$ and fresh culture medium $(100 \mu \mathrm{L})$ was added, the culture medium was discarded, the cells were washed again with $10 \mathrm{mM}$ PBS, and new culture medium $(100 \mu \mathrm{L})$ was added containing $10 \mu \mathrm{L}$ of the CCK- 8 reagent to each well. After $2 \mathrm{~h}$ of incubation, the absorbance at $450 \mathrm{~nm}$ of cell samples was measured with a UV-vis microplate absorbance reader (Bio-Rad model 689). The cell viability was calculated as follows

$$
\text { SR }(\%)=\frac{\text { Abs sample }}{\text { Abs blank }} \times 100
$$

where Abs sample is the absorbance at $450 \mathrm{~nm}$ for samples with NPs and Abs blank is the absorbance for controls without NPs.

In addition, some of the wells were also irradiated with a CW fiber-coupled diode laser source at $808 \mathrm{~nm}$ (50 W, Oclaro, Inc., San Jose, CA). The used power fluencies were 0.5, 1.0, and $3.0 \mathrm{~W} / \mathrm{cm}^{2}$ for $5 \mathrm{~min}$. After 18 and $42 \mathrm{~h}$, the cells were washed again and new fresh culture medium $(100 \mu \mathrm{L})$ was added with $10 \mu \mathrm{L}$ of the CCK-8 reagent to each well and measured as specified above.
4.13. Annexin V/Dead Cell Apoptosis Assay. HeLa and MDA-MB-231 cells were treated with PSS/DOXO/PLL/HAcoated, (PSS/DOXO/PLL) $2 / \mathrm{HA}$-coated, and PSS/PLL/HAcoated GNRs and with $2 \mu \mathrm{g} / \mathrm{mL}$ of free DOXO as a positive control for apoptosis. Untreated cells were used as a negative control. After $6 \mathrm{~h}$ of incubation with the hybrid NPs or free $\mathrm{DOXO}$, the culture medium was changed by fresh one and cells were illuminated with an $808 \mathrm{~nm}$ CW laser at several power intensities $\left(0,0.5,1\right.$, and $\left.3 \mathrm{~W} / \mathrm{cm}^{2}\right)$ for $5 \mathrm{~min}$. After 24 $\mathrm{h}$, the cells were trypsinized and redispersed in $500 \mu \mathrm{L}$ of fresh medium $\left(7.5 \times 10^{4}\right.$ cells $\left./ \mathrm{mL}\right)$. Then, $100 \mu \mathrm{L}$ of cells was mixed with $100 \mu \mathrm{L}$ of the Annexin V/Dead cell reagent (Muse Annexin V \& Dead Cell Assay Kit, Millipore, USA) and incubated for $20 \mathrm{~min}$ in the dark at room temperature. Finally, flow cytometry was perfomed using a Millipore Muse cell analyzer (Merck-Millipore, USA).

\section{ASSOCIATED CONTENT}

\section{S Supporting Information}

The Supporting Information is available free of charge on the ACS Publications website at DOI: 10.1021/acsomega.8b01591.

UV-vis spectra of DOXO-loaded GNRs; 3D reconstructed fluorescence microscopy image of cell-internalized particles; fluorescence microscopy images of GNR uptake and DOXO release at different time points; quantification of DOXO concentration within the hybrid particles; quantitative estimation of hybrid particles inside cells; temperature increases upon illumination of hybrid particles with NIR light; and TEM images of particle internalization (PDF)

\section{AUTHOR INFORMATION}

\section{Corresponding Authors}

*E-mail: eva.mailbox1@gmail.com (E.V.-A.).

*E-mail: pablo.taboada@usc.es (P.T.).

ORCID

Antonio Topete: 0000-0002-5448-0295

Pablo Taboada: 0000-0002-2903-7857

\section{Notes}

The authors declare no competing financial interest.

\section{ACKNOWLEDGMENTS}

Authors thank AIE for funding through Project MAT201680266-R. FEDER funds are also greatly acknowledged. E.V.A. and A.P. are grateful to the Spanish Ministerio de Economia y Competitividad for their FPU fellowships. Authors also especially thank staff of Instituto de Ortopedia y Banco de Tejidos Musculoesqueléticos of the Universidade de Santiago de Compostela for facilities to perform some of the in vitro cell experiments.

\section{REFERENCES}

(1) Siegel, R. L.; Miller, K. D.; Jemal, A. Cancer statistics, 2017. CaCancer J. Clin. 2017, 67, 7-30.

(2) Alexis, F.; Pridgen, E. M.; Langer, R.; Farokhzad, O. C. Nanoparticle technologies for cancer therapy. In Handbook of Experimental Pharmacology; Schafer-Korting, M., Ed.; Springer-Verlag: Berlin-Heidelberg, 2010; pp 55-86.

(3) Brigger, I.; Dubernet, C.; Couvreur, P. Nanoparticles in cancer therapy and diagnosis. Adv. Drug Delivery Rev. 2002, 54, 631-651. 
(4) Banerjee, D.; Sengupta, S. Nanoparticles in cancer chemotherapy. Prog. Mol. Biol. Transl. Sci. 2011, 104, 489-507.

(5) Davis, M. E.; Chen, Z.; Shin, D. M. Nanoparticle therapeutics: an emerging treatment modality for cancer. Nat. Rev. Drug Discovery 2008, 7, 771-782.

(6) Kwon, G. S.; Naito, M.; Yokoyama, M.; Okano, T.; Sakurai, Y.; Kataoka, K. Physical entrapment of adriamycin in $\mathrm{AB}$ block copolymer micelles. Pharm. Res. 1995, 12, 192-195.

(7) Gabizon, A.; Shiota, R.; Papahadjopoulos, D. Pharmacokinetics and tissue distribution of doxorubicin encapsulated in stable liposomes with long circulation times. J. Natl. Cancer Inst. 1989, 81, 1484-1488.

(8) Missirlis, D.; Kawamura, R.; Tirelli, N.; Hubbell, J. A. Doxorubicin encapsulation and diffusional release from stable, polymeric, hydrogel nanoparticles. Eur. J. Pharm. Sci. 2006, 29, $120-129$.

(9) Gillies, E.; Frechet, J. Dendrimers and dendritic polymers in drug delivery. Drug Discov. Today 2005, 10, 35-43.

(10) Chaudhuri, P.; Paraskar, A.; Soni, S.; Mashelkar, R. A.; Sengupta, S. Fullerenol-Cytotoxic Conjugates for Cancer Chemotherapy. ACS Nano 2009, 3, 2505-2514.

(11) Barbosa, S.; Topete, A.; Alatorre-Meda, M.; Villar-Alvarez, E. M.; Pardo, A.; Alvarez-Lorenzo, C.; Concheiro, A.; Taboada, P.; Mosquera, V. Targeted combinatorial therapy using gold nanostars as theranostic platforms. J. Phys. Chem. C 2014, 118, 26313-26323.

(12) Azizi, M.; Ghourchian, H.; Yazdian, F.; Bagherifam, S.; Bekhradnia, S.; Nyström, B. Anti-cancerous effect of albumin coated silver nanoparticles on MDA-MB 231 human breast cancer cell line. Sci. Rep. 2017, 7, 5178.

(13) Reichardt, W.; Hu-Lowe, D.; Torres, D.; Weissleder, R.; Bogdanov, A., Jr. Imaging of VEGF receptor kinase inhibitor-induced antiangiogenic effects in drug-resistant human adenocarcinoma model. Neoplasia 2005, 7, 847-853.

(14) Mulder, W. J. M.; Koole, R.; Brandwijk, R. J.; Storm, G.; Chin, P. T. K.; Strijkers, G. J.; de Mello Donegá, C.; Nicolay, K.; Griffioen, A. W. Quantum dots with a paramagnetic coating as a bimodal molecular imaging probe. Nano Lett. 2006, 6, 1-6.

(15) Manchester, M.; Singh, P. Virus-based nanoparticles (VNPs): Platform technologies for diagnostic imaging. Adv. Drug Delivery Rev. 2006, 58, 1505-1522.

(16) Lewinski, N.; Colvin, V.; Drezek, R. Cytotoxicity of nanoparticles. Small 2008, 4, 26-49.

(17) Tong, L.; Wei, Q.; Wei, A.; Cheng, J.-X. Gold nanorods as contrast agents for biological imaging: optical properties, surface conjugation and photothermal effects. Photochem. Photobiol. 2009, 85, $21-32$.

(18) DeLong, R.; Adam Wanekaya, C. M.; Chris Reynolds, Y.; Schaeffer, A.; Severs, T.; Wanekaya, A. Functionalized gold nanoparticles for the binding, stabilization, and delivery of therapeutic DNA, RNA, and other biological macromolecules. Nanotechnol., Sci. Appl. 2010, 3, 53-63.

(19) Kim, C.-k.; Ghosh, P.; Rotello, V. M. Multimodal drug delivery using gold nanoparticles. Nanoscale 2009, 1, 61-67.

(20) Chen, H.; Shao, L.; Li, Q.; Wang, J. Gold nanorods and their plasmonic properties. Chem. Soc. Rev. 2013, 42, 2679-2724.

(21) Weissleder, R. A clearer vision for in vivo imaging. Nat. Biotechnol. 2001, 19, 316-317.

(22) Hu, M.; Chen, J.; Li, Z.-Y.; Au, L.; Hartland, G. V.; Li, X.; Marquez, M.; Xia, Y. Gold nanostructures: Engineering their plasmonic properties for biomedical applications. Chem. Soc. Rev. 2006, 35, 1084-1094.

(23) Jin, S.; Ma, X.; Ma, H.; Zheng, K.; Liu, J.; Hou, S.; Meng, J.; Wang, P. C.; Wu, X.; Liang, X.-J. Surface chemistry-mediated penetration and gold nanorod thermotherapy in multicellular tumor spheroids. Nanoscale 2013, 5, 143-146.

(24) Dreaden, E. C.; Mackey, M. A.; Huang, X.; Kang, B.; El-Sayed, M. A. Beating cancer in multiple ways using nanogold. Chem. Soc. Rev. 2011, 40, 3391-3404.
(25) Dickerson, E. B.; Dreaden, E. C.; Huang, X.; El-Sayed, I. H.; Chu, H.; Pushpanketh, S.; McDonald, J. F.; El-Sayed, M. A. Gold nanorod assisted near-infrared plasmonic photothermal therapy (PPTT) of squamous cell carcinoma in mice. Cancer Lett. 2008, 269, 57-66.

(26) Huang, X.; El-Sayed, I. H.; Qian, W.; El-Sayed, M. A. Cancer cell imaging and photothermal therapy in the near-infrared region by using gold nanorods. J. Am. Chem. Soc. 2006, 128, 2115-2120.

(27) O’Neal, D. P.; Hirsch, L. R.; Halas, N. J.; Payne, J. D.; West, J. L. Photothermal Tumor Ablation in mice using near infrared absorbing nanoshells. Cancer Lett. 2004, 209, 171-176.

(28) Choi, J.-H.; Hwang, H.-J.; Shin, S. W.; Choi, J.-W.; Um, S. H.; $\mathrm{Oh}, \mathrm{B} . \mathrm{K}$. A novel albumin nanocomplex containing both small interfering RNA and gold nanorods for synergetic anticancer therapy. Nanoscale 2015, 7, 9229-9237.

(29) Yang, J.; Choi, J.; Bang, D.; Kim, E.; Lim, E.-K.; Park, H.; Suh, J.-S.; Lee, K.; Yoo, K.-H.; Kim, E.-K.; Huh, Y.-M.; Haam, S. Convertible Organic Nanoparticles for Near-Infrared Photothermal Ablation of Cancer Cells. Angew. Chem., Int. Ed. 2011, 50, 441-444.

(30) Huang, X.; El-Sayed, I. H.; Qian, W.; El-Sayed, M. A. Cancer cells assemble and align gold nanorods conjugated to antibodies to produce highly enhanced, sharp, and polarized surface Raman spectra: A potential cancer diagnostic marker. Nano Lett. 2007, 7, 1591-1597.

(31) Xiao, Y.; Hong, H.; Matson, V. Z.; Javadi, A.; Xu, W.; Yang, Y.; Zhang, Y.; Engle, J. W.; Nickles, R. J.; Cai, W.; et al. Gold nanorods conjugated with doxorubicin and cRGD for combined anticancer drug delivery and PET imaging. Theranostics 2012, 2, 757-768.

(32) Guo, S.; Huang, Y.; Jiang, Q.; Sun, Y.; Deng, L.; Liang, Z.; Du, Q.; Xing, J.; Zhao, Y.; Wang, P. C.; et al. Enhanced gene delivery and siRNA silencing by gold nanoparticles coated with charge-reversal polyelectrolyte. ACS Nano 2010, 4, 5505-5511.

(33) Grabinski, C.; Schaeublin, N.; Wijaya, A.; D’Couto, H.; Baxamusa, S. H.; Hamad-Schifferli, K.; Hussain, S. M. Effect of gold nanorod surface chemistry on cellular response. ACS Nano 2011, 5, 2870-2879.

(34) Ding, H.; Yong, K.-T.; Roy, I.; Pudavar, H. E.; Law, W. C.; Bergey, E. J.; Prasad, P. N. Gold nanorods coated with multilayer polyelectrolyte as contrast agents for multimodal imaging. J. Phys. Chem. C 2007, 111, 12552-12557.

(35) Alkilany, A. M.; Nagaria, P. K.; Hexel, C. R.; Shaw, T. J.; Murphy, C. J.; Wyatt, M. D. Cellular uptake and cytotoxicity of gold nanorods: Molecular origin of cytotoxicity and surface effects. Small 2009, 5, 701-708.

(36) Pastoriza-Santos, I.; Pérez-Juste, J.; Liz-Marzán, L. M. Silicacoating and hydrophobation of CTAB-stabilized gold nanorods. Chem. Mater. 2006, 18, 2465-2467.

(37) Ren, F.; Bhana, S.; Norman, D. D.; Johnson, J.; Xu, L.; Baker, D. L.; Parrill, A. L.; Huang, X. Gold nanorods carrying paclitaxel for photothermal-chemotherapy of cancer. Bioconjugate Chem. 2013, 24, 376-386.

(38) Fuks, J. Z.; Wadler, S.; Wiernik, P. H. Phase-I and phase-II in cancer therapy-2 cisplatin analogs and high-sode cisplatin in hypertonic saline or with thiosulfate protection. J. Clin. Pharmacol. 1987, 27, 357-365.

(39) Singal, P. K.; Iliskovic, N.; Li, T.; Kumar, D. Adriamycin cardiomyopathy: pathophysiology and prevention. FASEB J. 1997, 11, 931-936.

(40) Gottesman, M. M. Mechanisms of cancer drug resistance. Annu. Rev. Med. 2002, 53, 615-627.

(41) Ito, T.; Iida-Tanaka, N.; Niidome, T.; Kawano, T.; Kubo, K.; Yoshikawa, K.; Sato, T.; Yang, Z.; Koyama, Y. Hyaluronic acid and its derivative as a multi-functional gene expression enhancer: Protection from non-specific interactions, adhesion to targeted cells, and transcriptional activation. J. Controlled Release 2006, 112, 382-388.

(42) Aruffo, A.; Stamenkovic, I.; Melnick, M.; Underhill, C. B.; Seed, B. CD44 is the principal cell surface receptor for hyaluronate. Cell 1990, 61, 1303-1313. 
(43) Manocha, B.; Margaritis, A. Controlled release of doxorubicin from doxorubicin $/ \gamma$-polyglutamic acid ionic complex. J. Nanomater. 2010, 2010, 1-9.

(44) Vial, S.; Pastoriza-Santos, I.; Pérez-Juste, J.; Liz-Marzán, L. M. Plasmon coupling in layer-by-layer assembled gold nanorod films. Langmuir 2007, 23, 4606-4611.

(45) Kekicheff, P.; Spalla, O. Refractive index of thin aqueous films confined between two hydrophobic surfaces. Langmuir 1994, 10, $1584-1591$.

(46) Mulvaney, P.; Giersig, M.; Henglein, A. Surface chemistry of colloidal gold: deposition of lead and accompanying optical effects. J. Phys. Chem. 1992, 96, 10419-10424.

(47) Fröhlich, E. The role of surface charge in cellular uptake and cytotoxicity of medical nanoparticles. Int. J. Nanomed. 2012, 7, 55775591.

(48) Lapcík, L., Jr.; Lapcík, L.; De Smedt, S.; Demeester, J.; Chabrecek, P. Hyaluronan: Preparation, structure, properties, and applications. Chem. Rev. 1998, 98, 2663-2684.

(49) Blomberg, E.; Poptoshev, E.; Claesson, P. M.; Caruso, F. Surface interactions during polyelectrolyte multilayer buildup. 1 . interactions and layer structure in dilute electrolyte solutions. Langmuir 2004, 20, 5432-5438.

(50) Zhu, Y.; Shi, J.; Shen, W.; Dong, X.; Feng, J.; Ruan, M.; Li, Y. Stimuli-Responsive Controlled Drug Release from a Hollow Mesoporous Silica Sphere/Polyelectrolyte Multilayer Core-Shell Structure. Angew. Chem., Int. Ed. 2005, 117, 5213-5217.

(51) Pechenkin, M. A.; Möhwald, H.; Volodkin, D. V. pH- and saltmediated response of layer-by-layer assembled PSS/PAH microcapsules: fusion and polymer exchange. Soft Matter 2012, 8, 86598665.

(52) Burke, S. E.; Barrett, C. J. pH-Responsive Properties of Multilayered Poly(1-lysine)/Hyaluronic Acid Surfaces. Biomacromolecules 2003, 4, 1773-1783.

(53) Lee, S. K.; Han, M. S.; Asokan, S.; Tung, C.-H. Effective gene silencing by multilayered siRNA-coated gold nanoparticles. Small 2011, 7, 364-370.

(54) Huschka, R.; Zuloaga, J.; Knight, M. W.; Brown, L. V.; Nordlander, P.; Halas, N. J. Light-induced release of dna from gold nanoparticles: nanoshells and nanorods. J. Am. Chem. Soc. 2011, 133, 12247-12255.

(55) Cui, C.; Xue, Y.-N.; Wu, M.; Zhang, Y.; Yu, P.; Liu, L.; Zhuo, R.-X.; Huang, S.-W. Cellular uptake, intracellular trafficking, and antitumor efficacy of doxorubicin-loaded reduction-sensitive micelles. Biomaterials 2013, 34, 3858-3869.

(56) Zhang, Z.; Wang, J.; Nie, X.; Wen, T.; Ji, Y.; Wu, X.; Zhao, Y.; Chen, C. Near infrared laser-induced targeted cancer therapy using thermoresponsive polymer encapsulated gold nanorods. J. Am. Chem. Soc. 2014, 136, 7317-7326.

(57) Qhattal, H. S. S.; Liu, X. Characterization of CD44-mediated cancer cell uptake and intracellular distribution of hyaluronan-grafted liposomes. Mol. Pharm. 2011, 8, 1233-1246.

(58) Rowe-Horwege, R. W. Systemic Hyperthermia. In Encyclopedia of Medical Devices and Instrumentation; Webster, J. G., Ed.; John Wiley and Sons: New York, USA, 2006; pp 42-62.

(59) Hanahan, D.; Weinberg, R. A. The hallmarks of cancer. Cell 2000, 100, 57-70.

(60) Kerr, J. F. R.; Wyllie, A. H.; Currie, A. R. Apoptosis: A Basic Biological Phenomenon with Wideranging Implications in Tissue Kinetics. Br. J. Cancer 1972, 26, 239-257.

(61) Pérez-Hernández, M.; del Pino, P.; Mitchell, S. G.; Moros, M.; Stepien, G.; Pelaz, B.; Parak, W. J.; Gálvez, E. M.; Pardo, J.; de la Fuente, J. M. Dissecting the molecular mechanism of apoptosis during photothermal therapy using gold nanoprisms. ACS Nano 2015, 9, 5261.

(62) Fernández-Cabada, T.; Lopez de Pablo, C. S.; Serrano, A. M.; del Pozo-Guerrero, F. P.; Serrano-Olmedo, J. J.; Gómez, M. R. Induction of cell death in a gliblastome line by hyperthermis therapy based on gold nanorods. Int. J. Nanomed. 2012, 7, 1511-1523.
(63) von Maltzahn, G.; Park, J. H.; Agrawal, A.; Bandaru, N. K.; Das, S. K.; Sailor, M. J.; Bhatia, S. N. Computationally guided photothermal tumor therapy using long-circulating nanorod antennas. Cancer Res. 2009, 69, 3892-3900.

(64) Topete, A.; Alatorre-Meda, M.; Iglesias, P.; Villar-Alvarez, E. M.; Barbosa, S.; Costoya, J. A.; Taboada, P.; Mosquera, V. Fluorescent drug-loaded, polymeric-based, branched gold nanoshells for localized multimodal therapy and imaging of tumoral cells. ACS Nano 2014, 8, $2725-2738$

(65) Huff, T. B.; Tong, L.; Zhao, Y.; Hansen, M. N.; Cheng, J.-X.; Wei, A. Hyperthermic effects of gold nanorods on tumor cells. Nanomedicine 2007, 2, 125-132.

(66) Perrin, D. D. Buffers of low ionic strength for spectrophotometric pK determinations. Aust. J. Chem. 1963, 16, 572-578.

(67) Provencher, S. W.; Štêpánek, P. Global analysis of dynamic light scattering autocorrelation functions. Part. Part. Syst. Charact. 1996, 13, 291-294. 